\title{
The effects of activity conditioned in random CS/US training on performance in autoshaping
}

\author{
S. E. BRANDON and H. PAUL \\ Hofstra University, Hempstead, New York
}

\begin{abstract}
Random presentations of keylights and food retarded acquisition and suppressed asymptotic rates of keypecking in autoshaping. Sequences of 10 sessions of random training alternated with 10 sessions of autoshaping resulted in poor performance (in terms of both the acquisition and asymptotic indices) relative to a group that received sequences of CS-only (rather than random) training alternating with autoshaping. When the birds that previously were trained with the random sequence were exposed to CS-alone extinction, retardation of acquisition was alleviated but the asymptotic suppression was not (Experiment 1). Pigeons with a history of autoshaping without prior random training showed no asymptotic suppression when exposed to the random procedure. These birds, when switched between two-session sequences of random training alternating with two-session sequences of autoshaping, were able to (1) surpass pigeons that received CS-only rather than random treatment in terms of asymptotic levels of responding in autoshaping, and (2) showed improvement in extinction performance with repeated random/autoshaping sequences (Experiment 2). Detailed observations of pigeons in random training showed that stereotypic activity behaviors were acquired, and these generally persisted in autoshaping; the degree of change in these behaviors was related to asymptotic rates of keypecking in autoshaping (Experiment 3). The same kinds of behaviors were observed when pigeons initially were autoshaped, and these persisted in subsequent random and fixed-interval 10-sec training. We suggest that the suppression effect is reflected in activity, conditioned in random training, which persists in autoshaping (especially if the activity is compatible with the kinds of behaviors elicited by the autoshaping contingency itself), and that the effect may be a deficit due to performance factors rather than to associative learning.
\end{abstract}

If pigeons are exposed to random presentations of keylights (conditioned stimuli, CSs) and food (unconditioned stimuli, USs), subsequent keypeck acquisition is impaired relative to that of pigeons without such "random CS/US" exposure (Tomie, 1976a, 1976b, 1981). This "retardation" effect is very reliable and has provided support for several models of classical conditioning that focus on the acquisition either of associations (Mackintosh, 1975; Rescorla \& Wagner, 1972) or of performance tendencies (Gibbon \& Balsam, 1981) that interfere with the new conditioned response (CR). Typically, however, random CS/US training has another effect beyond that of slowing down the rate of acquisition of the CR. It also prevents responding from reaching asymptotic levels seen in animals without random pretraining (Balsam \& Schwartz, 1981; Durlach, 1984; Gamzu \& Williams, 1971, 1973; Randich \& LoLordo, 1979; Tomie, 1976a, 1976b, 1981; Tomie, Murphy, Fath, \& Jackson, 1980).

Some of the data from Experiment 1 were presented at the meeting of the American Psychological Association in Anaheim, August 1983, and some of the data from Experiments 3 and 4 were presented at the meeting of the Eastern Psychological Association in Boston, March 1985. We are indebted to Renee Pekmezaris and Julie Uran for their invaluable assistance with the data collection and analyses for these experiments. Requests for reprints should be sent to S. E. Brandon, who is now at the Department of Psychology, Box 11A Yale Station, Yale University, New Haven, CT 06520-7447, or to H. Paul, Department of Psychology, Hofstra University, Hempstead, NY 11550.
The persistence and the severity of the asymptotic suppression is notable. In a demonstration of the effect in pigeons, Gamzu and Williams (1973) reported that "initial exposure to the non-differential condition does not interfere qualitatively with auto-shaping nor with subsequent sustained responding, but does have a marked quantitative effect ... [which] was unanticipated, however, and represents a surprising non-reversibility of the order of experimental treatments" (p. 229). The suppression they showed was extreme: their "differential" group, which was given food only in the occasion of the keylight, reached an asymptote of approximately 85 to 90 responses/min, whereas the "nondifferential" (random CS/US) group reached an asymptote of approximately 15 to 20 responses $/ \mathrm{min}$. (It is of some interest to the present report to note that 2 of the 9 nondifferential birds attained rates as high as those of the differential birds-but see below.)

Although the asymptotic suppression effect of random CS/US training has received less attention than the effect of such training to impair acquisition, it poses some problems for the models of classical conditioning referred to already and for each account of the retardation effect per se. For example, both the Rescorla and Wagner (1972) and the Gibbon and Balsam (1981) models would lead to the expectation that even if contextual stimuli acquired the ability to impair initial responding to the CS, after extensive autoshaping these stimuli would become 
less excitatory than the CS so that keypecking could emerge and, once it occurred, it should reach levels comparable to those reached by birds without random pretraining (see Balsam \& Schwartz, 1981). The notion of "learned irrelevance" (Mackintosh, 1973) or general (Hall \& Honig, 1974) or CS-specific (Mackintosh, 1975) "inattentiveness," which can deal with the retarded acquisition effect, cannot explain what it is about random training that allows recognition of the role of the CS (and thus CR acquisition) but allows only minimal responding to the CS.

There are several other aspects of the effect of random training which also challenge current views of classical conditioning. For example, if random training is given to birds that already are keypecking, the treatment eliminates the response but keypecking almost immediately reappears again when the US is omitted altogether (Jenkins \& Lambos, 1983; Lindblom \& Jenkins, 1981). The immediacy of the effect makes it look as if response cessation was due to performance rather than associative factors. Similarly, it has been reported by Tomie (1985) that a keylight that is part of the context, in the sense that it is static throughout random training, will facilitate the acquisition of keypecking when that keylight is used as the autoshaping stimulus and when other aspects of the context are changed. This implies that excitatory contextual cues do not necessarily compete with keylights for the control of behavior. This fits with the further observation that in some cases-if a keylight is only weakly conditioned (Durlach, 1982) or if a discrimination between two keylights already has been established (Rescorla, Durlach, \& Grau, 1985)-excitatory contextual cues may facilitate performance. Perhaps the observation that there is no difference in activity (which is used as an index of contextual conditioning) between birds given signaled food (where context should have little control) and those given unsignaled food (where context should have more control) also reflects the apparent complex relationship between contextual conditioning, keylight conditioning, and the rules of performance.

Observations made with animals other than pigeons, and pertinent to the issue of what is learned in random CS/US training, led us to question the generality of the random effect across response measures. One observation is quite straightforward: direct (rather than transfer) measures of conditioning to contextual cues after random CS/US exposure in dogs showed that these stimuli were not excitatory, but neutral (Patterson \& Overmier, 1981). Another observation is that if headpoke into a food magazine is used as the CR, rats will headpoke more often during a light CS when that CS uniquely predicts food. If this training with CS-US pairings follows training with random CS/US presentations, there is no retardation or suppression of differential headpoking (Farwell \& Ayres, 1979). (These authors suggested that their results were a function of the compatibility of context CRs with light CRs, an issue we will consider also.) Lastly, goldfish also show no retardation or asymptotic suppression in a shift from nondifferential to differential CS-US procedures (Brandon, Satake, \& Bitterman, 1982). Such reports suggest to us that the data collected with the pigeon random CS/US preparation might be of limited generality and deserves closer scrutiny.

Thus, the experiments we report here were instigated by these questions in general, and by the inability of current models of classical conditioning to deal with the effects of random CS/US training on asymptotic autoshaping performance in pigeons in particular. The first two experiments were conducted as a demonstration of the acquisition and asymptotic retardation and suppression effects. In the last two experiments, we watched birds when they were switched from random training to autoshaping (Experiment 3) or from autoshaping to random training (Experiment 4).

\section{EXPERIMENT 1}

The rationale for the first intervention is based on the notion that the pigeon might overcome the asymptotic deficit (and reach high levels of responding) if it is given repeated transitions from random training to autoshaping. We know already that instrumental responding improves with each successive exposure to acquisition followed by CS-alone extinction (Brogden, Lipman, \& Culler, 1938; Bullock \& Smith, 1953; Clark, 1964; Couvillon, Brandon, Woodard, \& Bitterman, 1980). The same effect is seen after repeated exposure to extinction when the US is not omitted: Catania and Keller (1981) found increased rates of extinction with repeated exposure to the sequence variable ratio $20 \mathrm{sec}$ to variable time $10 \mathrm{sec}$. Improvement in reacquisition performance-which has been observed less frequently-was reported by Bullock and Smith (1953).

To produce the acquisition and asymptotic suppression effects in the present experiment, one group of birds was given random CS/US training followed by autoshaping. These birds then were given exposure to random training, followed by autoshaping, and so on; four such transitions occurred. As a control for the effects of exposure to the CS per se, and to make contact with the successive acquisition and extinction literature, another group was given repeated CS-only extinction/autoshaping. This group also served as a control against which to measure the effect of initial exposure to random training.

\section{Phase 1}

\section{Method}

Subjects. Twelve homing pigeons were obtained from a local breeder and maintained at approximately $80 \%$ of their free-feeding weights. The pigeons had free access to water in their individual home cages, which were in a temperature-controlled colony room. All 12 were naive.

Apparatus. The experimental chambers were two ventilated boxes, $34 \mathrm{~cm}$ wide $\times 30 \mathrm{~cm}$ long $\times 36 \mathrm{~cm}$ high, located in a lightand sound-attenuating room. On one wall of each chamber was a single $2.5-\mathrm{cm}$ Plexiglas key located $8 \mathrm{~cm}$ above a food aperture, 
$6 \mathrm{~cm}$ wide $\times 5 \mathrm{~cm}$ high, which contained a recessed grain hopper. The feeder was lit with a white 7.5-W light for each scheduled reinforcement period. The key was illuminated by an Industrial Electronics one-plane projector. The stimuli were a red (Kodak Wratten No. 25) or a green (No. 59) keylight. A 7.5-W houselight, located at the top of and behind the front wall, was lit throughout the experiment. All events and data records were controlled by a microprocessor located in a room adjacent to the experimental room.

Procedure. After the birds were trained to eat from the food hopper as soon as it was made available, they were randomly divided into two groups. Group RA (random-to-autoshaping) was given 10 sessions in which 10-sec keylight presentations, either red or green (balanced across subjects and conditions), were presented randomly with respect to 3.5-sec food presentations. Food was offered independently of responses to the key. The average interval between keylight presentations was $120 \mathrm{sec}$ (varying between 30 and $180 \mathrm{sec}$ ), and each session continued until $30 \mathrm{CSs}$ were given. (The number of US presentations, averaged over sessions, was 30 .) Group EA (extinction-to-autoshaping) was given 10 sessions of similar treatment except that food was omitted altogether. Session length for this group was matched, on a per-session basis, to that of Group RA so that each group received the same number of CSs.

The first transition followed the first 10 random (Group RA) or CS-only (Group EA) sessions. Both groups were exposed to an autoshaping procedure like the random procedure except that food always followed the CS immediately and no other USs were presented. Here, there were 30 CS-US pairings per session. Subsequent transitions followed: Group RA received 10 sessions of random, 10 of autoshaping, and so on. Group EA received 10 sessions of CSonly extinction, 10 of autoshaping, and so on. This continued until both groups had been exposed to four 10 -session series of autoshaping.

\section{Results and Discussion}

The data were analyzed in various ways in order to assess both within- and between-group differences in rate of acquisition and asymptotic levels of responding. Statistical analyses were performed using response rate (number of responses per minute to the CS) and response probabilities (percentage of trials within each session where at least one response to the CS occurred.) At no point in the experiment did color of the keylight (red or green) affect keypecking (Wilcoxon $T \mathrm{~s}>2, p s>.05$ ). Where appropriate, because of the high level of intersubject variance, tables and graphs show individual performance.

The retarded acquisition effect was evident in a betweengroups comparison of performance in autoshaping. Four of the 6 birds given random training were slower to acquire the tendency to keypeck than any of the birds in Group EA. Two random-trained birds showed an early tendency to keypeck, but one of these (Subject 60) ceased to peck after the first autoshaping series. Statistical analyses included the number of trials to the first recorded keypeck, the number of trials to five trials with at least one keypeck, and the number of trials to five consecutive trials with keypecks. These analyses showed that Group RA's first recorded keypeck took longer to occur than Group EA's in Autoshaping Series 3 and 4, and Group RA reached the criteria of five responses per trial and five consecutive trials with at least one response later in each autoshaping series (Mann-Whitney $U$ tests, ps $<.05$ ).
The suppression of asymptotic response levels was very severe, and also persisted throughout the series. Five of the 6 animals in Group RA failed to reach levels of keypecking comparable to those seen in Group EA. The exception was Subject $\mathbf{4 0}$, which also had shown no retardation effect. The mean number of responses per minute in each of the 10 sessions of Autoshaping Series 1 through 4 is depicted for both groups in Figure 1. Mann-Whitney $U$ tests (which included all subjects) showed significantly lower asymptotic levels in Group RA than in Group EA in all four series $(p s<.05)$.

Mean response probability for each subject in each session, Autoshaping Series 1 through 4 , is shown in Figure 2. In terms of response probability, 5 of the 6 birds in Group RA were lower than those of Group EA in all four autoshaping series $(U$ tests, $p s<.05$ ), and thus showed the suppression effect. However, the suppression using this measure is less striking than that using response rate. This observation fits with previous reports that the effect of random training is a quantitative rather than a qualitative one (Gamzu \& Williams, 1973).

Within-group analyses showed that asymptotic rates of responding stayed the same within each group throughout the autoshaping series (Wilcoxon $T \mathrm{~s}>0, p \mathrm{~s}>.05$ ). Performance in acquisition improved, however, from Series 1 to Series 2 for both groups. In terms of all three acquisition indices, the birds of Group RA were faster to begin to keypeck in Series 2, 3, and 4 than in Series 1 (Wilcoxon $T \mathrm{~s}<2, p s<.05$ ), although Subject 40 showed a strong tendency to respond from the beginning of training and Subject 60 failed to respond after Series 1 . Thus, there was some improvement after Series 1 for Group RA. However, because similar improvement was evident in Group EA (performance in Series 2, 3, and 4 was better than in Series 1), the retarded acquisition effect, in terms of a between-groups comparison, still was evident.

The pigeons became somewhat more facile with the extinction contingencies (CS-only or random) within the series, but the improvement was evident only from Series 2 to Series 3 for both groups. Analysis of the number of trials elapsed prior to the occurrence of the first trial, the first five trials, or five consecutive trials with no keypecking showed that Group EA improved from Series 2 to Series 3 for both groups. Analysis of the number of trials elapsed prior to the occurrence of the first trial, the first five trials, or five consecutive trials with no keypecking showed that Group EA improved from Series 2 to Series 3 (Wilcoxon $T s<2, p s<.05$ ).

Finding no improvement here in acquisition beyond the first acquisition and extinction sequence is not unique. North and Morton (1962) and Anger and Anger (1976) reported similar findings. It is possible that the extended exposure to the contingencies within each series contributed to this result. Anger and Anger used 8-day series and they also found no improvement. When improvement is observed, it is common to find that shorter series were 


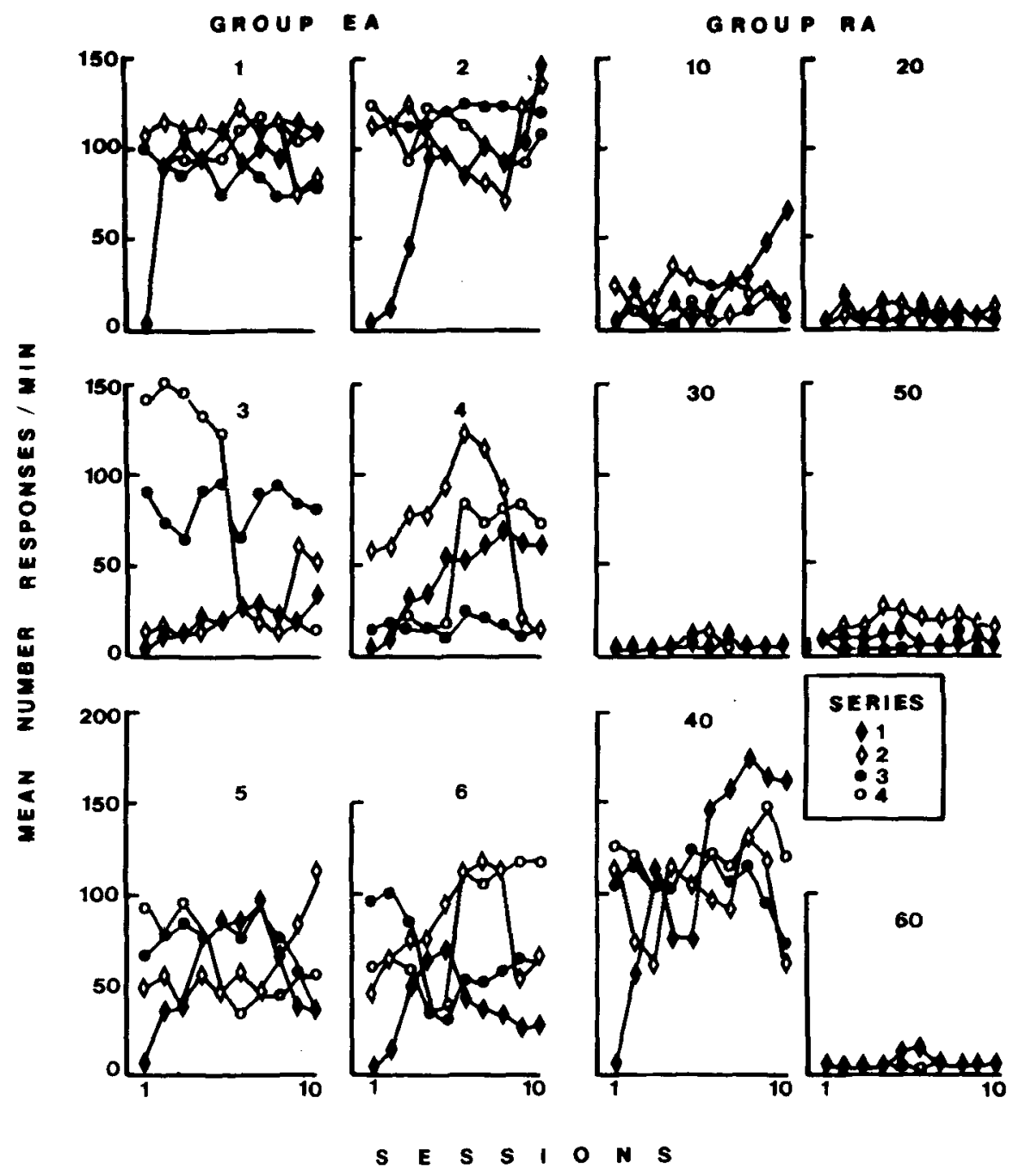

Figure 1. The mean number of CS responses per minute in each of the 10 autoshaping sessions of Series 1 through 4 for Group EA (Subjects 1-6) and Group RA (Subjects 10-60), Experiment 1, Phase 1.

used. For example, Bullock and Smith (1953) used 1-h series. In the present experiment, the long series (10 sessions) was used because the retarding effect of the random training appears most robust after this amount of training (see Tomie, 1981), and we were concerned with the persistence of the retardation over repeated acquisition sessions.

The main result here was a suppression of asymptotic levels of keypecking in autoshaping following random CS/US training. This suppression-relative to pigeons without such random training but with an equal amount of exposure to the CS alone-persisted despite repeated exposure to the autoshaping contingency itself. A second finding was some alleviation of the acquisition retardation effect in terms of within-group assessment of performance in each autoshaping sequence following the first. This improvement in autoshaping performance following the first sequence occurred whether birds initially were
CS-only trained or initially random-trained. It should be noted that Tomie et al. (Tomie, Hayden, \& Biehl, 1980; Tomie, Murphy, et al., 1980; Tomie, Rohr-Stafford, \& Schwan, 1981) found no such improvement in reacquisition with autoshaping following random training. However, Tomie used pigeons whose initial experience was with autoshaping; we used pigeons whose initial experience was with random training. Tomie also found, as we did here, that retardation of acquisition persisted in between-group comparisons. In other words, even though there may be some improvement within a group over repeated reacquisition, performance of birds exposed to random training never reaches levels attained by those without such treatment. Thus, these data, taken together with those reported by Tomie, suggest that the nature of the initial experience is a crucial variable.

The acquisition-retardation effect is alleviated by two manipulations. One is to change contextual stimuli be- 

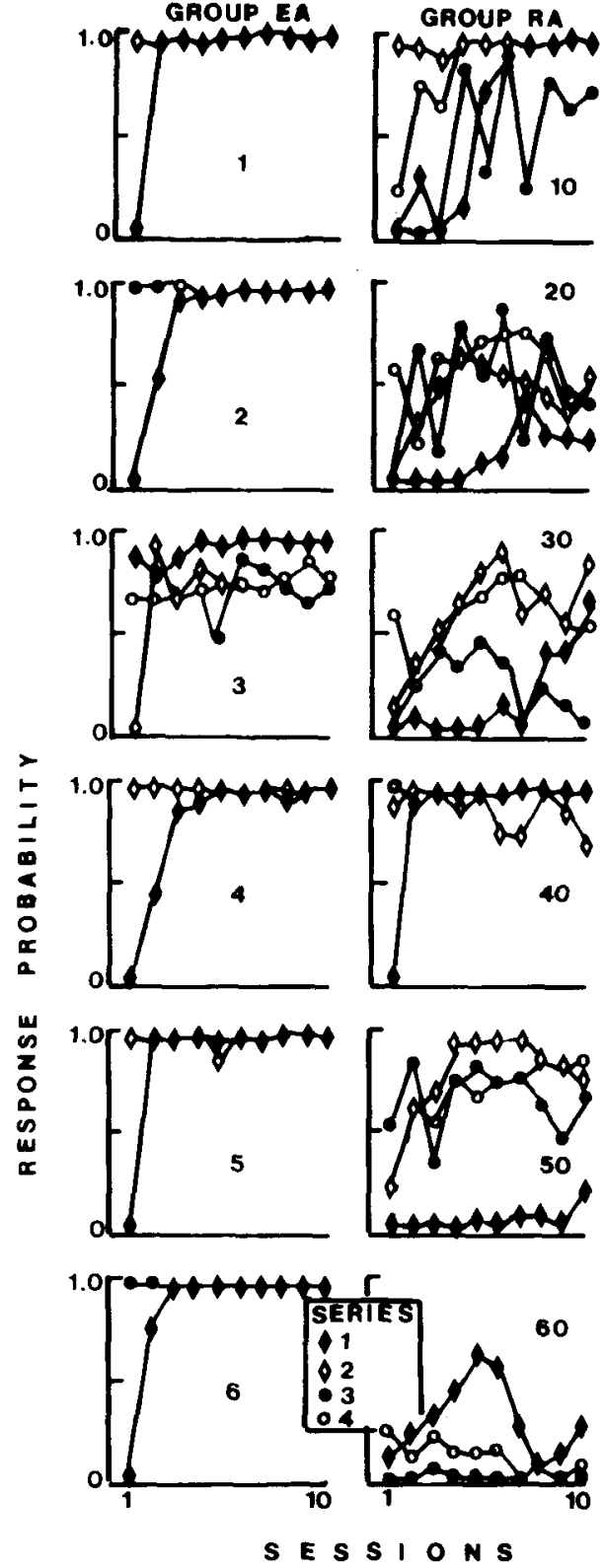

Figure 2. The probability of response to the $\mathrm{CS}$ in each of the 10 autoshaping sessions of Series 1 through 4 for Group EA (Subjects 1-6) and Group RA (Subjects 10-60), Experiment 1, Phase 1.

tween random CS/US training and autoshaping (Tomie, 1976b; Tomie, Murphy, et al., 1980; Tomie et al., 1981). The other is to insert two "context-extinction" sessions (when the birds are placed in the chamber without food) between random treatment and autoshaping (Tomie, 1976a). Both procedures facilitate keypecking in autoshaping. Close inspection of the data of Tomie et al. (Tomie, 1976b; Tomie, Murphy, et al., 1980) shows, however, that the asymptotic suppression effect may be still evident in the context-extinguished birds. Such a discrepancy indicates that the acquisition and asymptotic effects may be variably determined. In the second phase of the present experiment, we chose to examine the effect of CS-alone training on performance in autoshaping when that treatment occurred for a previously random CS.

\section{Phase 2}

\section{Method}

Subjects and Apparatus. The subjects and apparatus were the same as those used in Phase 1.

Procedure. Groups EA and RA each were divided into two new groups and given either consistent autoshaping (Subjects 1, 4, 5, 20,40 , and 50 ) or two sessions of CS-only extinction interpolated between every two sessions of autoshaping (Subjects $2,3,6,10$, 30 , and 60). The autoshaping and extinction procedures were identical to those of the autoshaping and CS-only extinction procedures used in Phase 1. Phase 2 continued for a total of 72 sessions, either 72 autoshaping sessions (for A/A subjects) or 18 2-day autoshaping sequences interpolated between 182 -day extinction sequences (for $\mathrm{A} / \mathrm{E}$ subjects).

\section{Results and Discussion}

Shown in Figure 3 are the mean number of responses per minute for each subject, pooled over 4-session blocks for 36 autoshaping sessions in Phase 2. The first block of six graphs (on the left) represent performance of $A / A$ subjects in the autoshaping sessions that occurred when $\mathrm{A} / \mathrm{E}$ subjects (second block of six graphs, on the right) also were autoshaped. (Performance in CS-only sessions for A/E subjects is not shown.) Note that Subjects 1 through 6 had been in Group EA and Subjects 10 through 60 had been in Group RA in Phase 1.

As is evident from this figure, extensive exposure either to autoshaping (Subjects 20,40, and 50) or to autoshaping interrupted by two-session periods of CS-only treatment (Subjects 10, 30, and 60) was not adequate to remove the asymptotic suppression of response rates due to the random CS/US training in Phase 1. The exception again was Subject 40, which responded vigorously throughout training (as in Phase 1).

Table 1 shows asymptotic response probabilities from Phases 1 and 2 (and 3). These were calculated from the mean probabilities in the last eight sessions of autoshaping in each phase. For Phase 1, these were consecutive sessions from the last autoshaping series. (Because these data also are represented in Figure 2, they are included in Table 1 for comparison purposes only.) In Phase 2, these eight sessions were interrupted by six (three 2-day) sessions of CS-only training for Subjects $2,3,6,10,30$, and 60 . Table 1 shows that response probabilities changed little from Phase 1 to Phase 2, with the exception of two birds, both from Group RA. One bird (Subject 20) showed a slight decrease in response probability in Phase 2; this bird had received continued autoshaping in this phase. The other bird (Subject 60) showed a substantial increase in the likelihood of responding in Phase 2. This bird had ceased to respond in Phase 1; in Phase 2, it had received autoshaping/CS-only treatment. (As can be seen in Figure 3, this improvement was not evident in terms of rate of responding for this bird.) 


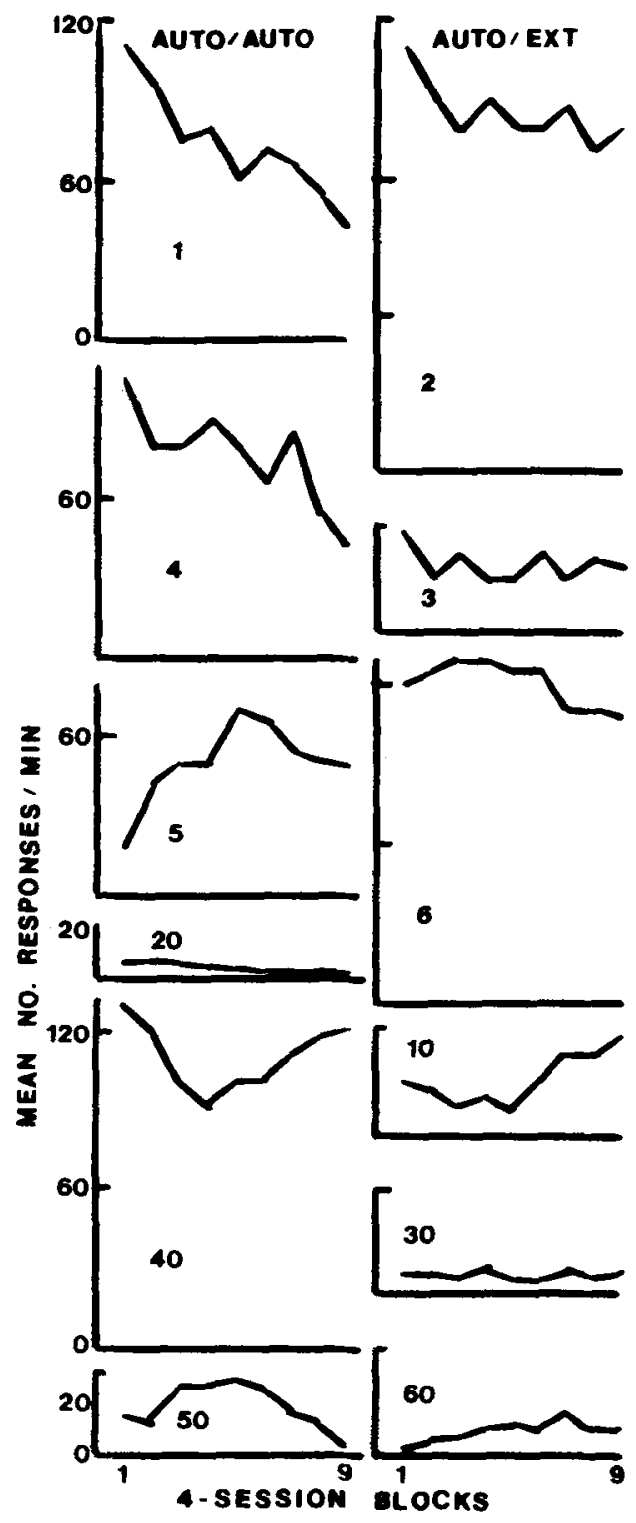

Figure 3. The mean number of CS responses per minute for each bird, pooled over four-session blocks in autoshaping, Experiment 1, Phase 2. The six graphs on the left represent performance of birds in Group $A / A$, and the six graphs on the right, performance of birds in Group $\mathbf{A} / \mathbf{E}$.

CS-only training removed the acquisition-retardation effect altogether: although, at the end of Phase 1, 4 of the random pigeons took more than 15 trials to respond at least once in the first autoshaping session of every series, by the end of Phase 2, all 6 birds of Group RA were responding at least once in the first one or two trials within each autoshaping session (independently of whether that session followed autoshaping or CS-only treatment). There was, in terms of this index, no difference between the birds of Group RA and those of Group EA from Phase 1 ( $U$ tests, $p s>.05$ ). Again, the difference between the persistence of the acquisition and asymptotic effects suggests that they may be influenced by different variables.

The birds of Group EA continued to respond at substantial levels in Phase 2 . The interpolated CS-only training had no obvious impact on their performance, although it might be argued that it prevented a decrease in rates of keypecking in autoshaping: 2 of the A/A birds (which had been in Group EA) showed a gradual decline in level of keypecking in this phase, whereas all $3 \mathrm{~A} / \mathrm{E}$ birds (formerly of Group EA) maintained their same level of keypecking.

The asymptotic suppression effect appeared thus to be little affected by the CS-alone training and not to be alleviated by extensive exposure to autoshaping. These data are unexpected in terms of context-blocking accounts of the effect of random training, which would lead us to predict that both extensive autoshaping and extensive CSonly treatment would weaken control by the context. Neither treatment had much effect on behavior in autoshaping. The observation that the suppression effect persisted suggests that whatever produced it is not affected (or may even be strengthened) by autoshaping or CS-alone treatments.

\section{Phase 3}

In the last phase of this experiment, all the birds were exposed to 10 continuous sessions of CS-only treatment. Then they were autoshaped using a new keylight. This was done to assess again the specificity and the persistence of the asymptotic suppression effect, and to measure possible transfer effects from Phase 2. We thought that the extended series of CS-only sessions might make that treatment more effective than it had been in Phase 2, and that the effect of such extinction treatment might be evident if the test was more substantial-that is, if the birds had continuous exposure to autoshaping. Finally, recovery in Phase 2 might have been hindered by the fact that we used the same CS as in Phase 1. Therefore, a new keylight was used in the autoshaping sessions of Phase 3.

Table 1

Mean Asymptotic Response Probabilities, Experiment 1

\begin{tabular}{|c|c|c|c|}
\hline Subject & End Phase 1 & End Phase 2 & End Phase 3 \\
\hline \multicolumn{4}{|c|}{ Group EA } \\
\hline 1 & 100 & 100 (Auto/Auto) & 100 \\
\hline 2 & 100 & (Auto/Ext) & 65 \\
\hline 3 & 74 & 83 (Auto/Ext) & 60 \\
\hline 4 & 100 & 100 (Auto/Auto) & 93 \\
\hline 5 & 87 & 90 (Auto/Auto) & 62 \\
\hline 6 & 100 & 100 (Auto/Ext) & 73 \\
\hline \multicolumn{4}{|c|}{ Group RA } \\
\hline 10 & 97 & 100 (Auto/Ext) & 64 \\
\hline 20 & 76 & 27 (Auto/Auto) & 10 \\
\hline 30 & 63 & 50 (Auto/Ext) & 48 \\
\hline 40 & 100 & 100 (Auto/Auto) & 100 \\
\hline 50 & 76 & 52 (Auto/Auto) & 33 \\
\hline 60 & 5 & 89 (Auto/Ext) & 84 \\
\hline
\end{tabular}




\section{Method}

Subjects and Apparatus. The subjects and apparatus were the same as in Phases 1 and 2.

Procedure. All birds were given 10 sessions of CS-only training with the keylights used in Phases 1 and 2 . Then a new keylight was introduced (green or red, balanced over subjects with the light that each had been given in the previous phases) and the animals were autoshaped as in Phases 1 and 2 . This training continued for 60 sessions.

\section{Results and Discussion}

The mean number of responses per minute at the end of 10 sessions of CS-only training was 8.5. Analyses of mean asymptotic probability and rate of responding in autoshaping showed that responding was not affected by whether the key color was red or green $(p s>.05)$.

Figure 4 shows the mean number of responses per minute, pooled over five-session blocks, for each subject in the autoshaping of Phase 3. The suppressive effects of the random CS/US training of Phase 1 are still evident. The only bird of Group RA (in Phase 1) to reach a substantial level of keypecking was again Subject 40 , which never had shown the effect in the first place. The birds of Group EA (Phase 1) continued to respond, although some showed a gradual decline in rate of responding,

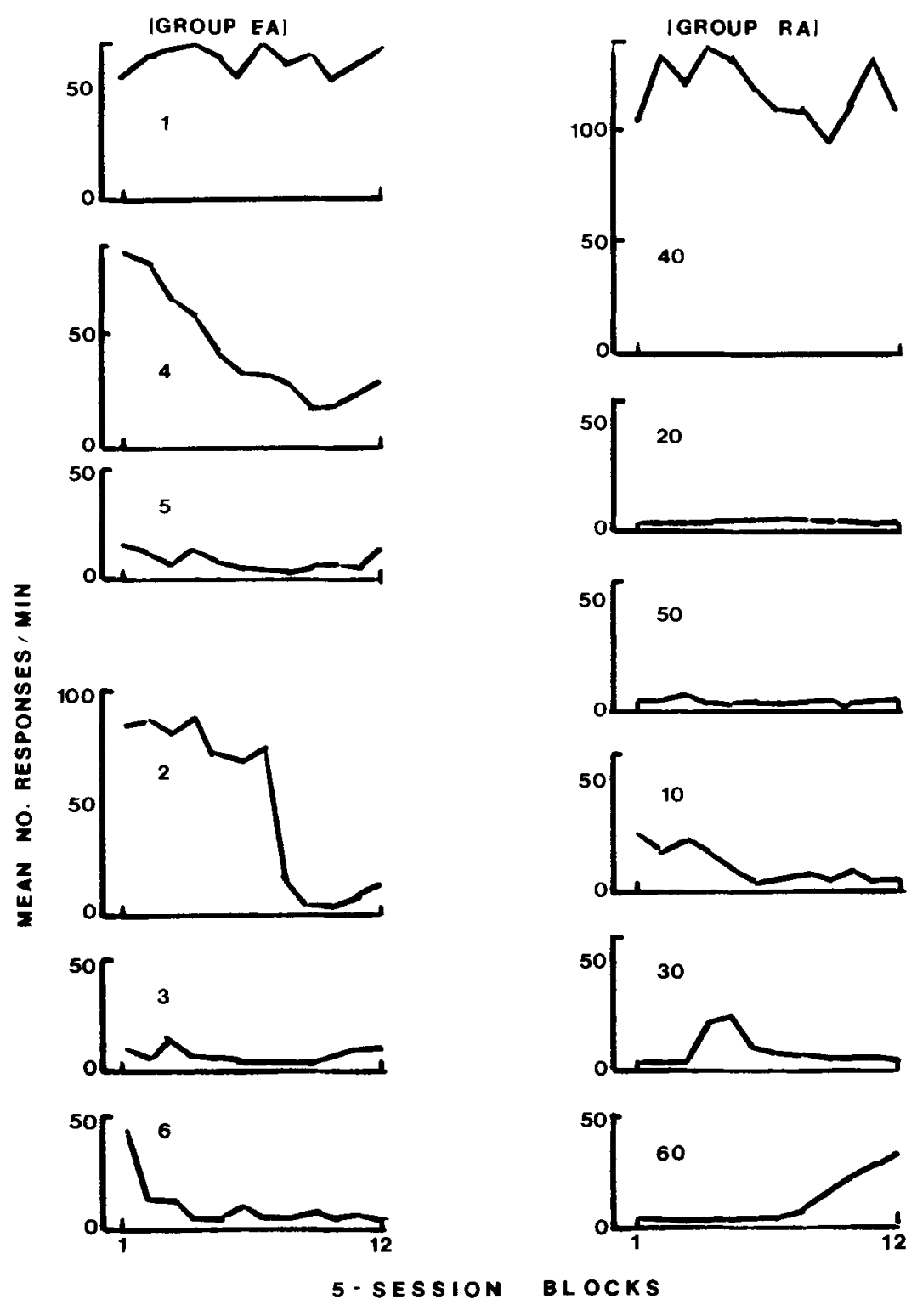

Figure 4. The mean number of $\mathrm{CS}$ responses per minute for each bird, pooled over five-seasion blocks in autoshaping, Experiment 1, Phase 3. The six graphs on the left represent performance of birds belonging to Group EA in Phase 1, and the six graphs on the right represent performance of birds belonging to Group RA in Phase 1 . 
perhaps reflecting some sort of "topographical drift" (see Herrnstein, 1966) over sessions.

Both extensive autoshaping and extensive CS-only training failed to reverse the suppression effect, even when a new keylight was used as the CS. The same conclusion can be made on the basis of the asymptotic response probability data shown in Table 1 . Subject $\mathbf{4 0}$ maintained a high probability of responding; of the remaining 5 birds, 3 showed a substantial decrease in response probability.

One bird of Group RA, Phase 1, did not show asymptotic suppression. It also did not exhibit any immediate or short-term retardation. The other 5 birds given random training showed both effects. This kind of betweensubject variable sensitivity to random training is not uncommon; note the two "nondifferential" birds of Gamzu and Williams (1973) described above. Rather than consider Subject 40 an anomaly, then, we might conclude that this bird acted the same as the other birds in that, following random training, it was consistent in its asymptotic performance in autoshaping-regardless of intervening treatments. The consistency within subjects, across treatments, in fact may be a crucial aspect of these data. It suggests that either the random-trained pigeons were impervious to autoshaping and CS-alone treatments or that the variables that were present in random CS/US training were present, and effective, in autoshaping and CSalone training as well.

To summarize the data from Phases 1 through 3, we found that random CS/US training, as opposed to CSalone training, suppressed asymptotic levels of keypecking even when the random treatment was interspersed with autoshaping. The asymptotic effect was not alleviated by 2-day sessions of CS-alone treatment or by an extended, 10-session CS-alone treatment followed by a change in key color. The acquisition effect was, however, attenuated by exposure to repeated sequences of autoshaping interpolated between random training: within-group analysis showed superior performance in the second autoshaping sequence relative to the first (but no further improvement beyond this). However, because this same improvement in autoshaping occurred for CS-alone birds as well as for birds given random training, it is difficult to conclude that the retarding effect of the random training was truly gone; between-group assessment showed that the birds with a background of random training were still worse than the birds with a background of CS-alone training in every autoshaping sequence. The acquisition differences between the two groups were removed when CS-alone treatment was given to the previously randomtrained birds: after such training, there were no differences, in terms of acquisition in autoshaping, between the performance of these birds and the birds formerly trained with CS only.

The persistence of the asymptotic suppression found here apparently was due to the fact that the initial training was with a random CS/US procedure. As noted already, asymptotic (unlike acquisition) effects seem to be determined by initial treatment (Tomie, 1976a; Tomie,
Murphy, et al., 1980). This determinacy is illustrated in the following experiment: When pigeons already are autoshaped, asymptotic suppression is not produced by random CS/US treatment.

\section{EXPERIMENT 2}

In Experiment 1, initial exposure to random CS/US training was seen to result in long-term and seemingly irreversible suppression of rates of keypecking in autoshaping. In Experiment 2, for one group of pigeons, initial exposure to autoshaping was followed by random training so that now we could examine the effect of random CS/US presentations on pigeons that already were pecking at high rates. For a control group, CS-alone training followed autoshaping, so that cessation of keypecking with this procedure could be compared with that found with the random procedure. Then, to permit assessment of improvement over such successive acquisition and extinction training, both groups were switched back and forth between autoshaping and their respective alternative treatments.

\section{Method}

Subjects and Apparatus. Fourteen naive pigeons served in this experiment. They were obtained and maintained as had been the pigeons in Experiment 1. The apparatus also was the same.

Procedure. All subjects were magazine trained as in Experiment 1 . Then 10 sessions of autoshaping were given, again using the Experiment 1 procedure. Immediately following autoshaping, the pigeons were divided into two groups, matched on the basis of asymptotic rates and probability of responding. For Group A, 2 CS-only sessions were given. These were identical to the autoshaping sessions, except that the food deliveries were omitted. For Group R, 2 sessions of random CS/US training were given. These also were identical to the autoshaping sessions, except that the CS and the US were programmed to occur randomly with respect to each other; the total number of CSs was the same as in Group A on CS-only days. Then both groups were given 2 more sessions of autoshaping, followed by 2 sessions with their respective extinction procedures, and so on. These 2 -session sequences continued for a total of 40 sessions: a total of 20 (10 2-session) autoshaping sessions and 20 (10 2-session) CS-alone or random CS/US sessions.

\section{Results and Discussion}

The pigeons readily acquired the keypeck response, reaching an asymptotic response level of $82 / \mathrm{min}$. Figure 5 shows the performance of both groups in the 10 sequences of 2-day autoshaping sessions alternated with 2-day extinction sessions. Median rates (number of responses per minute) to the CS in the 2-day autoshaping sessions are plotted over median rates to the CS in the two CS-only sessions; for Group $\mathbf{R}$, these session graphs represent performance in random CS/US training; for Group A, these are representative of performance in CS-only extinction.

Two aspects of these data are noteworthy. The first is the substantial level of responding seen in Group $R$ in autoshaping sessions. Not only is there no suppression of keypecking in this group, but response levels equaled those seen early in autoshaping and surpassed those seen 


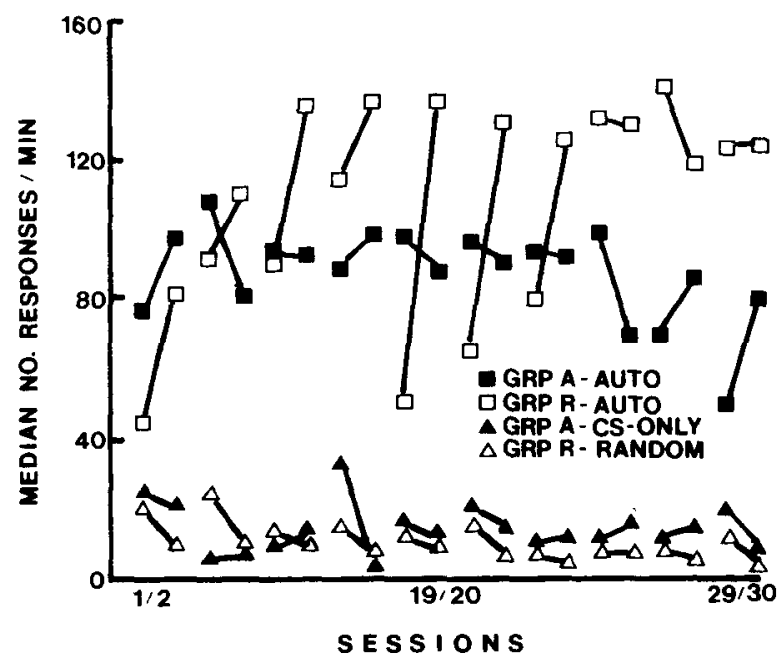

Figure 5. The median number of $\mathrm{CS}$ responses per minute for Group $A$ in autoshaping and CS-only extinction and for Group $R$ in autoshaping and random training. Autoshaping data are plotted over data representative of performance in CS-only and random $\mathrm{CS} / \mathrm{US}$ sessions, although autoshaping sessions were subsequent to CS-only or random CS/US training sessions (Experiment 2).

later in autoshaping in Group A. The differences between the groups were reliable in Sessions 1 and 2 in the last two autoshaping series ( $U$ tests, $p s<.05$ ). This difference tended to be greater in the second than in the first session of each series, but this effect was not statistically reliable across all sessions $(p s>.05)$. Thus, we found neither a suppression of asymptotic responding - in fact, we found facilitated keypecking - nor retarded acquisition in pigeons with a history of autoshaping experience that then were exposed to random training.

A second aspect of interest in these data is that both groups showed substantial improvement in extinction performance over the series. This can be seen more clearly in Figure 6, which shows median response rates to the CS blocked over three trials in CS-only or random treatment-Session 1 for Series 1 and 10. Although Group A showed a higher level of responding in the first trial of Series 10 than in the first trial for Series 1, its responding in Trials 6 through 10 was lower (Wilcoxon $T s<3$, ps $<.05)$. Group $R$ showed comparable responding in Trial 1 , but reliably less responding in Trials 3 through $10(T s<3$, ps $<.05)$.

Various accounts of improvement in extinction performance are feasible here. The birds may have learned about the physical (e.g., Bullock \& Smith, 1953) or memorial (e.g., Couvillon et al., 1980) aftereffects of reinforcement, or they may have acquired some sort of learning set (see Catania \& Keller, 1981). The latter may be the most parsimonious explanation in that it allows the same mechanism to explain performance in both groups; differentiation of the stimulus or memorial aftereffects of reinforcement versus nonreinforcement could work only for Group A. It should be noted that improvement in ex- tinction performance cannot be accounted for by models of conditioning that state that the cessation of responding in random training is dependent upon assumption of associative (Rescorla \& Wagner, 1972) or even nonassociative (Gibbon \& Balsam, 1981) control by contextual cues. The rapidity with which the random birds ceased and resumed keypecking, their improvement in extinction performance over the series, and their vigorous level of keypecking in autoshaping imply that CS-US associations were unaffected by the random training. In this sense, these data are reminiscent of previous reports (Brandon, 1981; Jenkins \& Lambos, 1983; Lindblom \& Jenkins, 1981) of keypecking that ceased in random training (given after autoshaping) but resumed when the birds were given CS trials with the US omitted.

The impressive level of responding maintained by Group $R$ in this experiment is quite unlike the performance of the birds that had initial random CS/US training in Experiment 1. The differences between the treatments are twofold. In Experiment 1, pigeons first were exposed to random CS/US training, and autoshaping followed; here, the reverse was true. In Experiment 1, the number of consecutive random and autoshaping sessions was 10; here, it was 2 . In view of the results reported by Tomie, Murphy, et al. (1980), which showed asymptotic suppression only in pigeons whose initial treatment was random, these data provide support for the notion that what was crucial to the suppression was the nature of the initial treatment.

The results of Experiments 1 and 2 suggest that initial exposure to random training is crucial to asymptotic suppression later in autoshaping, and that subsequent autoshaping and random CS/US procedures allow initial performance tendencies to perseverate despite a change in treatment from noncontingent to contingent (Experiment 1) or from contingent to noncontingent (Experi-

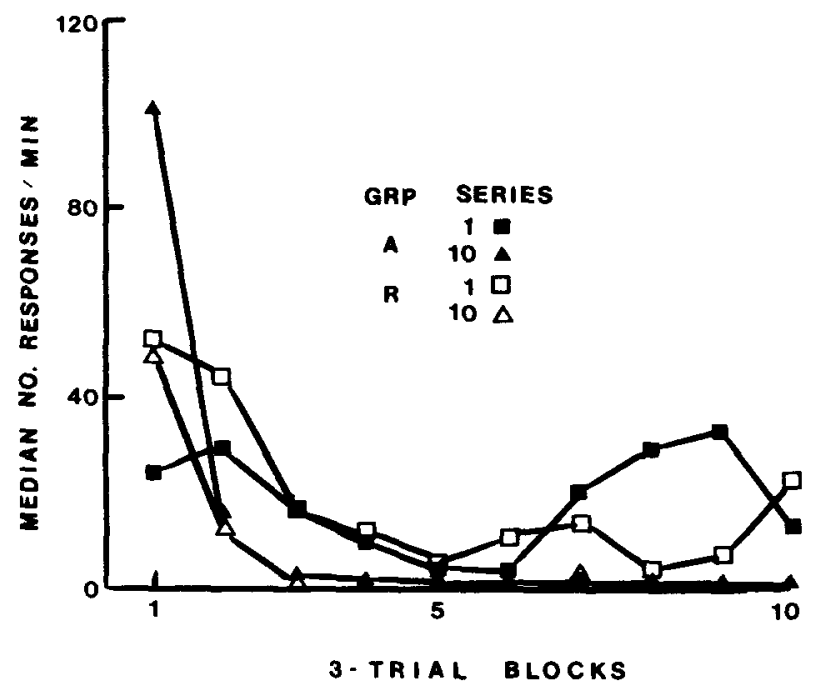

Figure 6. The median number of CS responses for Groups $A$ and $R$ in the first extinction session of Series 1 and the first extinction session of Series 10, pooled over three-trial blocks (Experiment 2). 
ment 2) presentations of CSs and USs. The inability of current accounts of classical conditioning to account for these various aspects of the suppression effect led us to consider yet another hypothesis, one that has been offered as an explanation of the retarded acquisition effect. This is the notion that random CS/US training establishes behaviors that compete with the autoshaping response and thus interfere with the acquisition of keypecking (Gamzu, Williams, \& Schwartz, 1973). For various sound reasons, this explanation has not been considered satisfactory. For example, it seems likely that behaviors that develop as a consequence of intermittent feeding are not incompatible with the autoshaping response (see Staddon \& Simmelhag, 1971). Similarly, there is evidence that acquisition of an instrumental response, such as the treadlepress, does not interfere with the acquisition of keypecking in autoshaping, at least not when the instrumental manipulanda are removed (Engberg, Hansen, Welker, \& Thomas, 1972). However, several investigators have reported that stereotypic behaviors are quite noticeable after random training (e.g., Durlach, 1984; Rescorla et al., 1985). It appears likely that the processes underlying such behaviors are complex. There may be some sort of interactionperhaps at the level of performance-between behaviors acquired in random training and the keypecking response in autoshaping. Tomie (1985) found that a static keylight that had been present throughout random US presentations was more likely than another keylight to facilitate keypecking when used in a subsequent autoshaping procedure. He accounted for this with the notion that the retarded acquisition effect itself was due to excitatory stimuli (such as contextual cues and keylights) that are conditioned in random training and elicit CRs whose topography is sometimes incompatible (in the case of contextual stimuli) and sometimes compatible (in the case of keylights) with keypecking. The source of this effect may be not adventitious reinforcement of "superstitious behavior" (cf. Skinner, 1948), but, rather, may be a function of the interaction between the nature of the stimuli (contextual cues or keylights) and the contiguity of these stimuli with reinforcement (see Holland, 1977).

There has been, however, no attempt to examine this hypothesis directly by watching birds in random training and autoshaping. Therefore, the next two experiments contain reports of observations made of pigeon behavior during random training and subsequent autoshaping (Experiment 3) and during autoshaping and subsequent random training (Experiment 4).

\section{EXPERIMENT 3}

In Experiment 3, 24 birds were observed periodically in random CS/US training and in subsequent autoshaping. The experiment consisted of two parts. In Part 1, 9 birds were observed at the end of random training and in early and late autoshaping. In Part 2, 15 birds were observed in early, middle, and late random training and late autoshaping. We chose to watch the birds, rather than to record more gross measures of activity, because this is a method that offers some advantages if stereotypic behavior is of concern (see Davis, Hubbard, \& Reberg, 1973). We had as our initial model the detailed reports of Staddon and his colleagues (e.g., Innis, Simmelhag-Grant, \& Staddon, 1983; Reberg, Innis, Mann, \& Elizenga, 1978; Staddon \& Simmelhag, 1971) of observations of pigeon behavior in fixed-time and variable-time schedules of food delivery.

\section{Method}

Subjects. The subjects were 24 naive pigeons obtained from the same source and maintained in the same manner as those of the previous experiment.

Apparatus. A single chamber and microprocessor identical to those described already were used here. A closed-circuit TV camera was placed in front of the observation window of the chamber for each training session (whether or not observations were made). This allowed an observer to view the entire chamber via a monitor in an adjacent room. The experimental room itself was dark, but a 7.5-W houselight illuminated the chamber.

Procedure. A standard observation procedure was used throughout this series of experiments. After the first $10 \mathrm{~min}$ of the session, the next reinforcement initiated a 5-min observation period, during which an observer noted the behavior of the bird by checking off descriptive categories every $3 \mathrm{sec}$. The categories, based partly on the work of Staddon and Simmelhag (1971) and partly on pilot studies, were as follows: (1) keypecking, (2) key-directed head movements, (3) magazine-directed head movements (including eating from the hopper), (4) pacing back and forth, facing the front (key and hopper) wall, (5) pacing back and forth, facing one of the side or rear walls, (6) standing, facing the front wall, (7) standing, facing away from the front wall, (8) flapping wings, and (9) turning around $\left(180^{\circ}\right)$. Observations made in test and pilot sessions when food was omitted showed that behavior before the first reinforcement was typical of behavior after the first reinforcement and that the behaviors were not dependent upon delivery of food. The observers were blind with regard to any experimental expectancies. Interobserver reliability indices, generated on the basis of concurrent independent observations made in sample sessions, averaged .92 .

In Part 1, 9 naive pigeons were given 30 sessions of random CS/US training and were observed in Sessions 26, 27, 28, 29, and 30. Then they were autoshaped and observed again in the 1st and 10th autoshaping sessions (Sessions 31 and 40).

The details of the procedure were as follows. Nine pigeons were magazine trained until they reached criterion, which was to approach and eat from the food hopper as soon as it was raised. This required from three to seven sessions in which the bird was placed in the chamber with a food cup or with the hopper raised until it ate, and then when the hopper was raised five times. The behavior of each bird was noted for each magazine training session. Random CS/US training was identical to that used in the random sequences of Experiment 1 , Phase 1 . This training continued for 30 sessions, then autoshaping commenced for a total of 10 sessions. For all 9 birds, the autoshaping program was the same as that used in Experiment 1.

In Part 2, 15 additional naive birds were magazine trained, then random trained and autoshaped in the same manner as in Part 1, with two exceptions: (1) 25 (rather than 10) autoshaping sessions were given, and (2) half the birds were autoshaped with a procedure in which the average intertrial interval was identical to that used in random training, and the remaining birds were given intervals that were half as long. This was done in order to examine the sensitivity of the stereotypy observed in random training to a change in the density of the food presentations. These birds were observed in Sessions $1,2,10,20$, and 30 of random training and in Sessions 20 and 25 of autoshaping (Sessions 50 and 55). 


\section{Results and Discussion}

As in Experiment 1, data for individual birds are described because of the high between-subject variance, and because the pattern of results is discerned only by inspection of the behavior of individual birds.

The results of the observations made in Phase 1 are shown on the left-hand side of Figure 7, which gives the percentage of time during which particular behaviors were observed for each bird over five consecutive random CS/US sessions (Sessions 26 through 30). For each bird, the order in which each behavior is graphed within each session represents that bird's typical (majority) order in which the behaviors were observed between successive food deliveries. For example, Subject 51 would eat, then stand briefly, pace facing a side wall or turn briefly toward a side wall, and then pace the front wall until the next food presentation. The numbers next to the subject identification digits represent the trial in autoshaping during which the first keypeck occurred and the asymptotic rate and probability of keypecking (averaged over Sessions 38-40), respectively.

Most of the birds were very active in random training, and, with one exception, the typical behavior was pacing. The exception was Subject 59, which sat quietly throughout the session. Intercorrelation analyses showed that the percentage of observation time spent pacing-front in Session 26 was correlated with pacing-front in Sessions $27(r=.95), 28(r=.96), 29(r=.98)$, and $30(r=.95)$. (All correlations reported here were statistically significant at $p<.05$ unless otherwise noted.) Pacing-side was similarly consistent; observations for Session 26 correlated with those for Session $27(r=.90), 28(r=.87)$, $29(r=.85)$, and $30(r=.86)$. Standing still was consistent also; observations for Session 26 correlated with those for Session $27(r=.78), 28(r=.80), 29(r=.75)$, and 30 $(r=.69)$. Similar descriptions of stereotypic behaviors have been provided already for birds in fixed-time and variable-time schedules of reinforcement by Staddon and Simmelhag (1971); the kinds of behaviors observed here appear to be the same as those labeled "interim" behaviors in these previous reports. The present data also are consistent with more informal observations of stereotypy and of a high level of general activity for pigeons in random or quasi-random CS/US training (Durlach, 1982; Rescorla, Durlach, \& Grau, 1985; Hall \& Honig, 1974), in variable-time schedules (Buzzard \& Hake, 1984), and when free reinforcements are delivered to a pigeon that is keypecking already (Herrnstein, 1966; Skinner, 1948). What we add to these reports is an indication that these behaviors are not entirely food-elicited and a quantification of the degree of stereotypy engendered by the random CS/US training.

Figure 7 (right panels) shows the behaviors of each bird in the 1st and 10th sessions of autoshaping (Sessions 31 and 40). Again, the order in which each behavior is graphed within each session represents the most frequent order in which the behaviors occurred in the period of time between reinforcements.
A general pattern is evident here: the birds that showed relatively little variation in stereotypic behavior between random training and the final session of autoshaping (Subjects 51 and 59) showed the lowest asymptotic rates of keypecking. Subjects that showed somewhat greater change (Subjects 52, 55, 56, and 61) showed higher asymptotic rates, and those that changed the most (Subjects 62 and 63 ) showed the highest asymptotic rates. The exception was Subject 58, whose behavior was quite disrupted by the autoshaping procedure but whose final response level was mediocre. Information as to whether the change in stereotypy preceded or followed the keypecking was not provided by these data.

The results of the observations from Part 2 are described in Figure 8. This figure shows the mean percentage of time during which the most frequent behavior of each bird was observed in the 1st, 10th, and 30th sessions of random training and in the 20th and 25th autoshaping sessions (Sessions 50 and 55). Below the subject identification digits are three numbers. The first is the total number of trials that elapsed prior to the first recorded keypeck, and the second and third are the asymptotic rate and probability of keypecking in autoshaping averaged over the 20th-25th sessions (Sessions 50-55). " $D$ ' identifies the birds that received the denser CS/US schedule in autoshaping.

All the birds were inactive in magazine training, and most of the birds (12 of 15) stood facing front or side walls; any activity that was observed (i.e., in the remaining 3 birds) was hopper-directed. On the other hand, observations made later in random training showed that 13 of the 15 birds had become very active and that all 15 birds displayed the same dominant behavior throughout random training; thus, stereotypic behaviors developed. Since these were emerging already by Random Session 2 , this development was quite rapid.

As in Part 1, there appeared to be some relationship between degree of change in stereotypic behavior and final asymptotic rates of keypecking in autoshaping. Of the 7 birds whose asymptotic level of keypecking was 0, 5 (Subjects 14D, 18D, 20, 21D, and 25) showed virtually no change in pacing from random training to autoshaping. The other 2 birds (Subjects 10 and 24D) changed the orientation of their pacing. Of the 5 birds that acquired keypecking at moderate rates, 2 showed categorical behavioral changes (Subjects 9D and 12D) and 1 (Subject 15) showed a change in direction of pacing. The remaining birds (Subjects 19 and 23) showed no categorical change whatsoever, although the variance of behaviors increased somewhat. The birds that showed the highest asymptotic levels of keypecking (Subjects 13D, 16D, and 22) underwent substantial changes in behaviors between random and final autoshaping sessions; they were not pacing in random training, but did pace (and keypeck) in autoshaping.

Two measures provided significant correlations with speed of acquisition of keypecking in autoshaping. One was pacing: the more often pacing was observed in random training, the slower the bird was to keypeck $(r=-.69)$. 

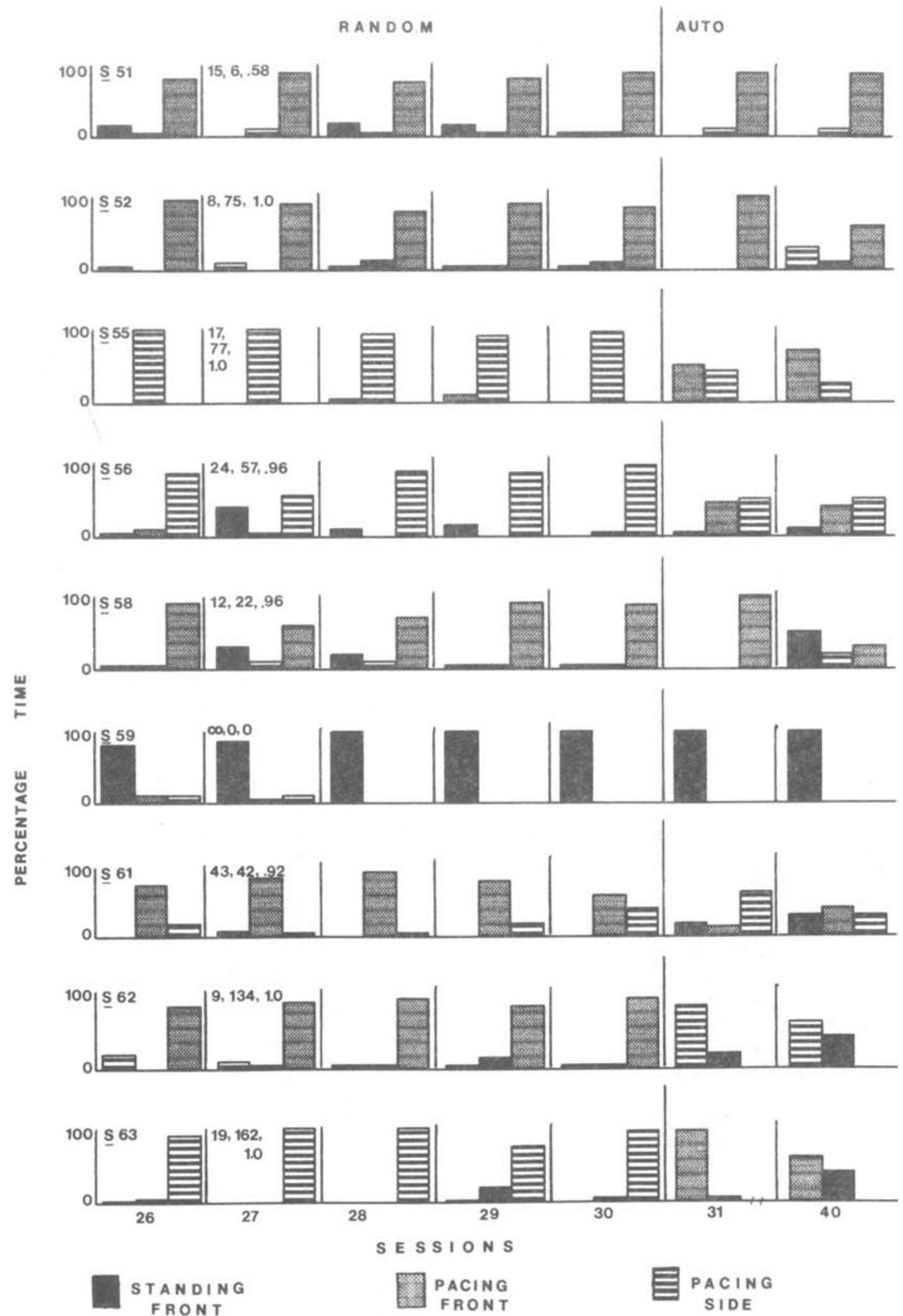

Figure 7. The percentage of observation time each bird spent engaged in a particular behavior within each session, in five consecutive random CS/US sessions (left panels) and in the first (31) and last (40) autoshaping sessions (right panels), Experiment 2, Part 1. The order in which each behavior is graphed within each session, for each bird, represents the most frequent order in which the behaviors were observed in that session between successive deliveries of food. The numbers next to the subject-identification digits represent the trial of the first keypeck, asymptotic rate of responding, and asymptotic probabilities of response, respectively. 




Figure 8. The percentage of observation time each bird spent engaged in its most frequent behavior in the 1st (R1), 10th (R10), and 30th (R30) random sessions and in the 50th (A50) and 55th (A55) autoshaping sessions, Experiment 4, Part 2. The numbers below the subject-identification digits represent the trial of the first keypeck, asymptotic rate of responding, and asymptotic probability of response, respectively. 
The other measure was asymptotic rate: the sooner the bird acquired keypecking, the higher its final rate of pecking $(r=.49)$. Although final asymptotic rates of keypecking in autoshaping were not reliably predicted by any particular behavior in random training, the phi correlation coefficient, calculated on the basis of the presence or absence of pacing in random training and the presence or absence of asymptotic keypecking in autoshaping, was -.66 . This indicates some inverse relationship between pacing in random training and keypecking in autoshaping. It may be noteworthy, therefore, that the three highest levels of keypecking were displayed by birds that were not pacing in random training. Unexpectedly, the density of CS-US pairings had no systematic effect on stereotypic behavior patterns, nor did it affect rate of acquisition or asymptotic levels of response (Mann-Whitney $U$ tests, $p s>.05$ ).

A more detailed analysis of the birds' behaviors in autoshaping showed that, despite the infrequency of keypecking in most of the birds even after 25 sessions of autoshaping, 12 of the 15 birds showed reliable changes in behavior during the CS. The birds that showed the highest asymptotic rates (Subjects 13D, 16D, and 22) were, of course, keypecking. Five birds with mediocre asymptotic rates (Subjects 9D, 12D, 15, 19, and 23) were observed to be pecking around the key or making key-directed motions in the air during the CS. Of the 7 birds that may have pecked occasionally in autoshaping but whose final level of response was 0,4 switched the direction of their pacing during the CS (Subjects 10, 20, 25, and 21D).

Because the random and autoshaping procedures used in Parts 1 and 2 were identical (all subjects were given 30 sessions with random training, followed by at least 10 sessions of autoshaping), the data from Parts 1 and 2 were combined in order to quantify the relationship between amount of change in behavior and rates of keypecking in Sessions 8, 9, and 10 of autoshaping. (It should be noted here that the birds in Part 2 had reached asymptote by the 10th autoshaping session, but that additional sessions were given in order to give nomresponders more time to acquire the CR.) A percent change index was calculated, based on the difference in percentage of time spent in each behavior in random (Session 30) versus autoshaping (Session 40) training. A stepwise multiple regression analysis showed that this index accounted for $21.6 \%$ of the total variance in final asymptotic rates of keypecking $[F(1,21)$ $=5.79, p<.05]$. However, the same analysis showed that percent change was not as successful in accounting for the variance in acquisition rate $\left(R^{2}=13.15, p>.05\right)$, suggesting again that acquisition and asymptote might be differentially determined. A multiple discriminant analysis showed that Parts 1 and 2 were not distinguishable in terms of any dependent variable.

These results provide some support for the idea that specific behaviors, evident after random training, may affect level of keypecking in autoshaping. What we found here was a positive correlation between the degree of change in nonkeypecking behaviors that were established in random CS/US training and the final asymptotic level of keypecking in autoshaping. No single behavior observed in random training, however, was found to reliably predict asymptotic levels of keypecking in autoshaping, although pacing in random training reliably retarded speed of acquisition and there was some suggestion that not pacing was more likely to result in keypecking. A study reported by Locurto, Travers, Terrace, and Gibbon (1980) is pertinent here. These investigators observed what they called keypeck "incompatible behaviors" in unrestrained pigeons early in autoshaping. These behaviors were pacing or weaving back and forth, often facing front. Because restrained birds did not show these incompatible behaviors and were faster to acquire the keypeck response, the authors concluded that the "strength and nature of competing responses are related to speed of acquisition for unrestrained subjects" (p.19). These results are consistent with those found here.

We also found evidence that the specific activities, and the overall level of activity, were acquired behaviors. They were not observed in magazine training, nor were they seen in the first session of random training. They began to appear reliably in the second session of random training, and then they persisted with very little variance; we found virtually no differences in the behaviors of individual birds in Sessions 2,10,20, and 30. This observation is consistent with previous studies that report intermittent feeding results in rapid conditioning to contextual cues (Balsam, 1984, 1985; Rescorla et al., 1985). The fact that the density of CS-US pairings in autoshaping had no effect on this activity-a finding inconsistent with other reports that general activity in pigeons increases with greater density and magnitude of reinforcement (Killeen, Hanson, \& Osborne, 1978)-is in accord with the notion that the activity behaviors were not just food-elicited.

The question of whether specific activity tendencies weakened, thus allowing the keypecking to emerge, or whether the keypecking suppressed various activities can be addressed here only indirectly. However, the degree of change in specific behaviors was not related to acquisition of keypecking, and there was no observation that general or specific activities decreased prior to the emergence of keypecking. These results make it seem probable that although specific activities may serve as a source of competition for the keypecking response, the two are not mutually exclusive and emergence of keypecking is not dependent upon the cessation of these behaviors. Rather, the associative processes responsible for the emergence of keypecking and the maintenance of specific activities appear to be independent of each other. It might be that keypecking reflects light-food associations and activity reflects alternative associations (such as context-food, or contextresponse), and the two interact at the peripheral level only. In any case, the stereotypic behaviors observed here do not themselves illuminate the underlying cause of asymptotic response suppression in autoshaping following random training.

These data may provide some insight into one of the anomalies about the relationship of keylight and context conditioning referred to already-namely, that general 
levels of activity remain high even when autoshaped keypecking emerges (Balsam, 1984, 1985; Durlach, 1984; Rescorla et al., 1985)-even though it is thought that keypecking occurs at the expense of control by contextual cues, as measured by generalized activity (Durlach, 1984). What we suggest, on the basis of the present data, is that if there is a decrease in the effectiveness of context cues to control behavior when autoshaping is successful, this change is evident more in a change in the specific nature of the CR than in overall level of activity.

The purpose of the last experiment was to address, again, the issue of the compatibility of activity CRs with keypecking. We faced the possibility that we might always fail to find evidence for or against compatibility because the observations were not detailed enough or because we looked for the wrong behavior. However, because we had no indication as to how the observations should be changed, we chose instead to use the same observational method and to look for compatibility by observing birds in autoshaping first. It seemed that, since keypecking would be substantial without prior random training, by definition "incompatible responses" would not be present. Then we observed the same birds when they were switched either to a random CS/US schedule or to a fixed interval (FI) schedule with the same FI- and CS-interval duration. Predicting that the FI schedule would maintain a higher level of keypecking, we thought that differences between random and FI birds might give us some information about the influence of acquired activity on keypecking. They would also provide some data on the role of adventitious reinforcement in the maintenance of the activity.

\section{EXPERIMENT 4}

Balsam (1984) reported that a high asymptotic level of autoshaped keypecking was positively correlated with a high level of general activity in ring doves. A similar finding was reported for pigeons by Pear and Eldridge (1984). On the basis of these reports, we expected a substantial amount of general activity in the present experiment, in which we observed pigeons that had been autoshaped and were keypecking. We were concerned with the similarity of this activity to the behaviors observed in random CS/US training (where the birds had received no previous autoshaping). Because all the birds in the present experiment would be keypecking, any alternative activity observed must be compatible with that response.

Another issue that concerned us was the role of reinforcement in the maintenance of stereotypic activity. Locurto et al. (1980) suggested that adventitious reinforcement played little role in the behaviors they saw prior to the emergence of keypecking when birds were observed in autoshaping, because they noted a sudden shift to a consummatory-like terminal response, in the course of the autoshaping, despite continued activity-reinforcer contiguity. In the present experiment, we followed autoshaping with a schedule that allows a more direct assessment of the role of strict response-reinforcer contiguity: the birds were switched from autoshaping either to a random CS/US schedule (which permits activity-reinforcer contiguity) or to an FI schedule, in which only keypecking can immediately precede reinforcement. An FI schedule was chosen because it could be made similar to the autoshaping procedure (in which a fixed CS-US interval is used), with the only procedural difference being in the contingency of reinforcement upon response to the key.

\section{Method}

Subjects and Apparatus. Fifteen naive pigeons served as subjects. They were maintained in the same manner as the birds of the previous experiments.

Procedure. All 15 birds were magazine trained (using the procedure described previously) and then autoshaped for 14 sessions using a red or green keylight (balanced across subjects) as the CS. The procedure was identical to that used in Experiment 3, in which the ITI averaged $120 \mathrm{sec}$. The pigeons were observed in Sessions 11 and 14. Six of these birds subsequently were given FI 10-sec training with the same keylight. The only change for these birds was the addition of the FI response-reinforcer contingency. The remaining 9 birds were given random CS/US training. For these birds, the keylight and food no longer were paired; the random program was the same as that used in Experiment 3. This training continued for all 15 birds for 14 sessions. The birds were observed for the entire first FI or random session, and for $5 \mathrm{~min}$ in Sessions 25 and 28 (the 11 th and 14th FI or random sessions). The observation procedure was the same as that used in Experiment 3.

\section{Results and Discussion}

After 10 and 13 sessions of autoshaping, the pigeons were observed to be engaged in much the same kinds of activity (when the CS was off) as seen in autoshaping for the pigeons of Experiment 3 (which had been exposed initially not to autoshaping, as were the present birds, but to random CS/US training). In these non-CS periods, all 15 birds were pacing rapidly, either in front of the hopper or facing the side walls. There was no effect of key color ( $p$ s $>.05$ ). The results of the observations made in Sessions 11 and 14 (autoshaping) and Sessions 25 and 28 (random or FI) are shown in Figure 9. These graphs represent the percentage of time each bird spent engaged in its most frequently observed behavior.

The dominance of pacing behaviors, as well as the general stereotypy of each bird, is obvious. Correlations between percentage of observed time each bird spent engaged in particular behaviors in Sessions 11 and 14 were positive and statistically significant for keypecking $(r=.63)$, key-directed activity $(r=.68)$, pacing-front $(r=.71)$, pacing-side $(r=.59)$, and standing-front $(r=.68)$. (For hopper-directed activity, $r=.40, p>.05$; for standing facing side walls, $r=.44, p>.05$.) Pacing behaviors did not correlate with asymptotic level of keypecking (correlation coefficients ranged from .02 to $.25, p s>.05$ ), but this may have been due partly to the limited range of both indices.

Keypecking was extinguished rapidly in the transition session for the random birds. The mean number of re- 


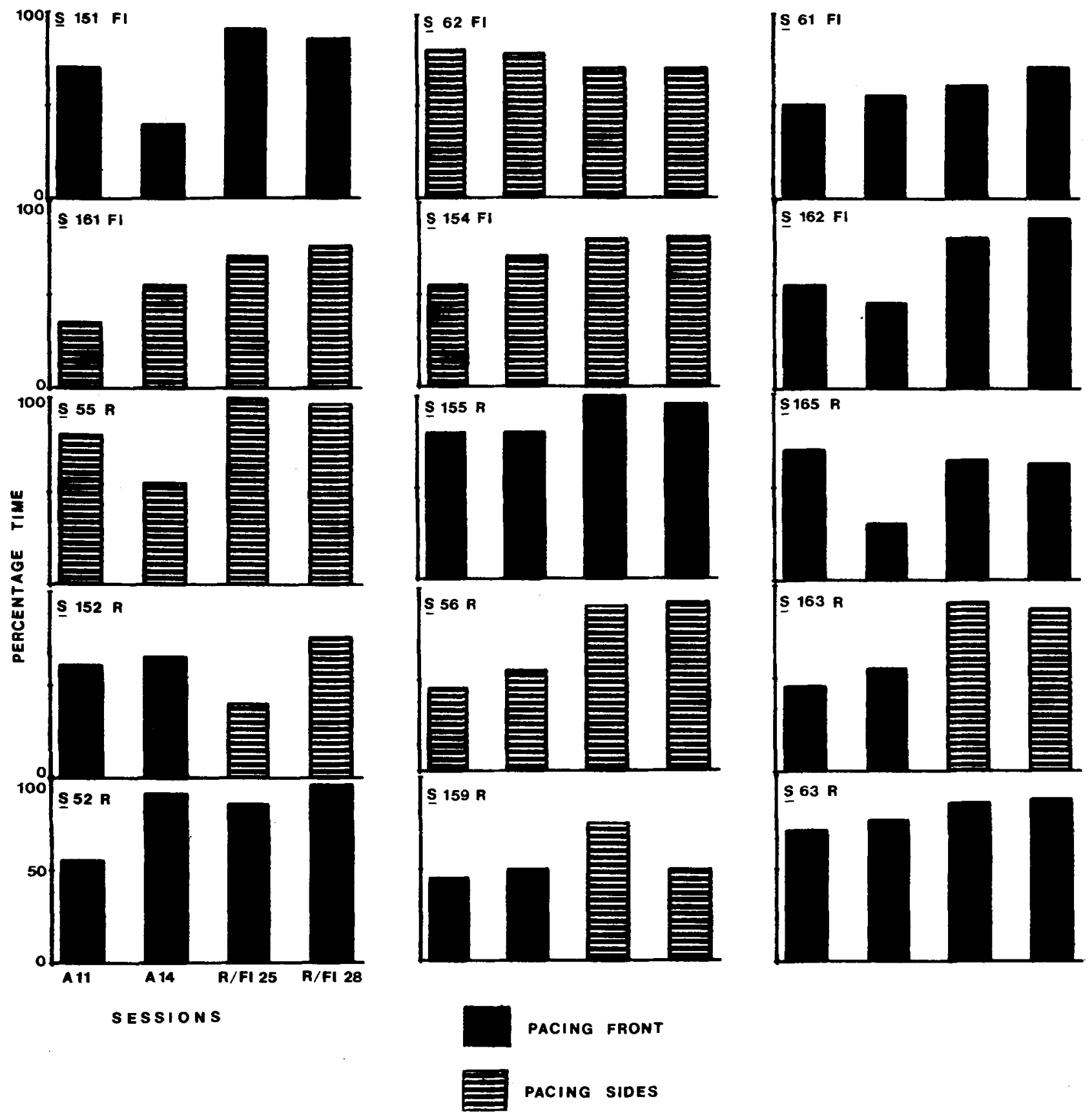

Figure 9. The percentage of observed time each bird spent engaged in its most frequent behavior in the 11th (A11) and 14th (A14) autoshaping sessions and in the 25th (R/FI 25) and 28th (R/FI 28) subsequent random or FI 10-sec sessions.

sponses per minute over the $30 \mathrm{CS}$ presentations began at 76 and ended at 0 . Keypecking increased in the first FI session for the FI birds; the mean number of responses per minute for this session began at 82 and ended at 125 .

Observations of this transition session showed little change in non-CS-time behaviors for most of the birds, despite changes in rates of keypecking. For the FI birds, there was virtually no disruption; the behaviors that were dominant in autoshaping continued to occur prior to keypecking. Table 2 shows the percentage of times that keypecking during the CS was preceded by Behaviors 1 through 7 (keypecking, key-directed activity, hopper activity, pacing-front, pacing-side, standing-front, and standing-side, respectively) in the transition session for the FI birds. The consistency of these birds is apparent. This table also shows the percentage of time each behavior oc- 
Table 2

\begin{tabular}{|c|c|c|c|c|c|c|c|c|c|c|}
\hline \multirow[b]{2}{*}{ ubject } & \multicolumn{7}{|c|}{$\begin{array}{c}\text { Transition Session: } \\
\text { Behavioral Category* }\end{array}$} & \multicolumn{2}{|c|}{$\frac{\text { Behavioral Category }}{\text { Dominant In: }}$} & \multirow[b]{2}{*}{ Changes } \\
\hline & $1 \dagger$ & 2 & 3 & 4 & 5 & 6 & 7 & Auto & FI/Rand & \\
\hline \multicolumn{11}{|c|}{ FI Group } \\
\hline 151 & 0 & 0 & 0 & 93 & 0 & 0 & 4 & 4 & 4 & 18 \\
\hline 62 & 0 & 7 & 0 & 0 & 86 & 7 & 0 & 5 & 5 & 18 \\
\hline 61 & 0 & 8 & 17 & 68 & 8 & 8 & $\mathbf{0}$ & 4 & 4 & 16 \\
\hline 161 & 0 & 0 & 7 & 0 & 93 & 0 & 0 & 5 & 5 & 20 \\
\hline 154 & 0 & 0 & 0 & 0 & 100 & 0 & 0 & 5 & 5 & 1 \\
\hline 162 & 0 & $\mathbf{0}$ & 0 & 94 & 6 & 0 & $\mathbf{0}$ & 4 & 4 & 9 \\
\hline \multicolumn{11}{|c|}{ Random Group } \\
\hline 55 & $\mathbf{0}$ & 0 & 0 & 0 & 82 & 12 & 6 & 5 & 5 & 41 \\
\hline 155 & 0 & 0 & 0 & 59 & 29 & 0 & 12 & 4 & 4 & 54 \\
\hline 165 & 0 & 0 & 0 & 57 & 29 & 14 & 0 & 4 & 4 & 42 \\
\hline 152 & 0 & 6 & 12 & 0 & 70 & 12 & $\mathbf{0}$ & 4 & 5 & 40 \\
\hline 56 & 7 & 14 & o & 0 & 72 & 7 & 0 & 5 & 5 & 25 \\
\hline 163 & 0 & 0 & 0 & 7 & 53 & 27 & 13 & 4 & 5 & 100 \\
\hline 52 & 0 & 0 & $\mathbf{0}$ & 100 & 0 & 0 & 0 & 4 & 4 & 21 \\
\hline 159 & 7 & 0 & 0 & 33 & 47 & 0 & 14 & 4 & 5 & 89 \\
\hline 63 & 0 & 0 & 0 & 100 & 0 & 0 & 0 & 4 & 4 & 24 \\
\hline
\end{tabular}

*For FI birds, these figures are the percentage of observed time each behavior preceded keypecking; for random birds, they are the percentage of time each behavior preceded reinforcement. $\dagger 1=$ keypecking, $2=$ key-directed activity, $3=$ hopper activity, $4=$ pacing-front, $5=$ pacing-side, $6=$ standing-front, $7=$ standing-side. $\ddagger$ Number of changes from one behavioral category to another in the transition session.

curred prior to reinforcement in the same session for the random birds. Six of the birds continued to exhibit the behaviors that had been dominant in autoshaping. Three birds did not (Subjects 152,163, and 159), and for each of these birds, the behavior that occurred most frequently prior to reinforcement in the transition session was the same behavior that dominated performance in the subsequent random sessions. For purposes of comparison, this table also shows which behavioral category had been dominant in autoshaping and which category subsequently was dominant in final FI or random training.

Table 2 also shows the variability in behavior (labeled "Changes") for each bird in the transition session in terms of "categorical changes," defined as a switch from one behavioral category to another (with the exception of starting and stopping keypecking during the CS and starting and stopping hopper activity during the US). In this session, a great deal more variance occurred in the random birds than in the FI birds (Mann-Whitney $U$ test, $p<.001$ ). It is likely that such variance was the result of repeated exposure to the keylight in the absence of food (in random CS/US schedules, the CS essentially is on CSalone extinction). There are previous demonstrations that when conditioned responses are extinguished, the topography of the responses increase in variability (Antonitis, 1951; Warden \& Lubow, 1942). This kind of variability in the random birds might be the basis for the greater degree of overall change in dominant behaviors in this group relative to that seen in the FI birds.

Figure 9 shows what happened to the frequency of pacing behaviors after the pigeons had been exposed to FI 10-sec (subjects labeled "FI') or to random CS/US (subjects labeled " $R$ ") training for 11 and 14 sessions. The category of dominant behavior remained the same for all 6 FI birds. For example, if the pigeon was pacing-front in autoshaping, this behavior continued during the FI schedule. The correlations between pacing-front and pacing-side in Session 14 of autoshaping and Session 28 of FI training were considerable $(r=.82$ and $r=.90$, respectively). The same was true for 6 of the 9 random birds; the 3 others switched the direction of their pacing. There was also somewhat greater variance in observed behaviors for this group. Although the correlation between pacing-side in Autoshaping Session 14 and the same behavior in Random Session 28 was significant $(r=.86)$, pacing-front behavior was not as reliable $(r=.32$, $p>$.05).

Perhaps the most important aspect of these data is the high level of pacing seen in the autoshaped birds. A great deal of general activity has been described already for pigeons in autoshaping (Balsam, 1984, 1985; Durlach, 1984; Locurto et al., 1980; Pear \& Eldridge, 1984). The present data are consistent with these previous reports. What we had hoped to see, and did not, was a difference in the nature of this activity for pigeons that were and those that were not trained with a random CS/US schedule prior to autoshaping. We can note, however, that there appeared to be greater consistency among birds that initially were autoshaped than among those that initially were randomtrained. Although quantitative comparisons between experiments can be made only with caution, Experiments 3 and 4 used identical autoshaping and random procedures and, 
in Experiment 3, 18 out of 24 birds were observed to be pacing in random training, whereas in the present experiment all birds ( 15 out of 15 ) were observed pacing in autoshaping. This suggests that the autoshaping contingency itself may be more likely than the random treatment to produce pacing behavior.

We lack any straightforward support for the notion that adventitious reinforcement played a role in the maintenance of stereotypic activities in random training. We found the same or greater persistence of activity in the FI birds than in the random birds when both were switched from autoshaping. It is true, however, that the test was faulty; it confounded the effects of activity-reinforcer contiguity with those of CS extinction, both of which occurred for the random birds but not for the FI birds. As was noted, there was more variance produced in the random than in the FI birds in the transition session. It is possible that once new behaviors (produced by the omission of the US after the CS) occurred in the random birds, a reinforcement process accounted for the persistence of those behaviors. We might also consider that, for the FI birds, as a result of their autoshaping experience, the keylight served as a secondary reinforcer (see Rashotte, Griffin, \& Sisk, 1977) whose potency was maintained by continued keylight-food pairings. Thus, the operative processes may have been the same for the FI and the random birds.

\section{GENERAL DISCUSSION}

Many aspects of these data are not accounted for in terms of context-conditioning explanations of the effects of random CS/US training on performance in autoshaping (Gibbon \& Balsam, 1981; Rescorla \& Wagner, 1972; Tomie, 1981). The finding that random presentations of keylights and food retarded the acquisition of keypecking is, of course, compatible with these models; the fact that the suppression of asymptotic level of responding persisted despite the eventual acquisition of the CR is not, nor is the fact that this asymptotic effect was not alleviated by extensive exposure to autoshaping or by $\mathrm{CS}+$ context extinction treatment (Experiment 1). The flexibility of the pigeons to switch back and forth between keypecking in autoshaping and not keypecking in random training suggests that random treatment does not interfere with CSUS associations-an aspect of these data that is compatible with the Gibbon-Balsam model but not the RescorlaWagner model. However, neither model would expect that performance in autoshaping would be facilitated by intervening random training or that performance in random training would improve over successive exposures to random training alternating with autoshaping (Experiment 2 ).

We considered the possibility that these various effects might be due to specific behaviors that were conditioned in random training. To explore this idea, we observed pigeons in various procedures: in early and later random CS/US training and in a subsequent shift to autoshaping; in autoshaping when there was no prior random training; and when autoshaped birds were switched to random or
FI training. In random training, we found a great deal of stereotypy and between-subject variability, which persisted from the second session of random training through autoshaping. The observation that the activities were very consistent and stereotypic, that they developed in the course of training, and that they occurred prior to the first delivery of food within each session made it seem likely that they were conditioned to the context and were not just due to the intermittent delivery of food.

We found that pacing behavior in random training reliably resulted in slower acquisition of keypecking in autoshaping. There also was some indication that behaviors other than pacing, conditioned in random training, were likely to correspond with higher asymptotic levels of keypecking in autoshaping. There was no single behavior, however, that could be used to reliably predict asymptotic levels of keypecking in autoshaping, although we did find that asymptotic rates were positively related to an overall change in behavior patterns observed after the autoshaping contingency was in effect. As an explanation of the suppression effect, however, this is post hoc; we are left with the idea that the suppression occurs to the extent that behaviors generated by random training are compatible with those generated by autoshaping, but that which behaviors occur varies from bird to bird (note also Subject 40 in Experiment 1). Likewise, we found no evidence that when pigeons were switched from random training to autoshaping, a specific behavior ceased and then keypecking to the CS emerged. Nor did we find that when pigeons were switched from autoshaping to random training, a nonkeypecking behavior developed in random training and then persisted during the CS onset and prevented keypecking (and thus could account for the cessation of pecking).

The general persistence of pacing during the switch from random training to autoshaping (in Experiment 3) was mirrored in the results of Experiment 4. There, $100 \%$ of the pigeons were observed to be pacing in autoshaping. The pacing persisted in subsequent FI training and, to a somewhat lesser extent, in random training. What we found, thus, in Experiments 3 and 4, was that pacing is quite compatible with keypecking-although it may slow the development of the response-and that both the random training and the autoshaping contingency promote acquisition of pacing behavior. This led us to suspect that pacing does not reflect context-US associations exclusive of (or at the expense of) CS-US associations.

We also observed that when pigeons were switched from autoshaping to random training, there was greater variability between subjects in the types of behaviors displayed than when they were switched to FI training. This greater disruption was probably due to the fact that the CS seldom was followed by food for the random birds but was always followed by food for the FI birds. For the birds most disrupted by experience with the CS alone, there was a somewhat greater likelihood that the pattern of behaviors that eventually emerged was different from that seen in the autoshaping. There was little evidence that adventitious reinforcement was a factor in the behavior of the birds in random training. This conclusion is simi- 
lar to that reached on the basis of previous investigations of pigeon behavior in other situations of free reinforcement (see, e.g., Killeen et al., 1978; Staddon \& Simmelhag, 1971; Timberlake \& Lucas, 1985).

An unexpected finding was that random-trained birds engaged in CS-specific behaviors in autoshaping, even if they failed to develop the keypecking response. This raises the question of whether there is any actual associative negative transfer effect following random training. Perhaps CS-specific behaviors in random birds develop as quickly as keypecking in naive birds and, therefore, random keylight-food presentations do not interfere as much with CS-specific learning as with CS-specific keypecking. Another unexpected finding was that there was no effect of intertrial interval (i.e., density of reward within the session) on acquisition or asymptotic behavior in autoshaping following random training (Experiment 3 ). Intertrial interval has been shown to have a powerful effect on acquisition in autoshaping for naive birds (Gibbon, Baldock, Locurto, Gold, \& Terrace, 1977). It follows either that the random-trained pigeon is impervious to variables to which the naive bird is sensitive or that some variables affect birds differently after random training.

The context-blocking notion has been most powerful in view of Tomie's (1981) data, which provide a demonstration that a change in contextual cues alleviates the retardation effect of random training on acquisition in autoshaping. However, it does not predict the asymptotic effect, and it is silent on many of the issues raised here. We would like to outline some alternative-or supplementary-ideas that might be useful in thinking about the effects of random training.

The first is the notion that random CS/US training results in the acquisition of "S1- $\mathrm{R}$ " associations, where " $\mathrm{S} 1$ " represents contextual cues and " $R$," the conditioned portion of the activity initially generated by intermittent food presentations. These associations are dependent upon the simple frequency with which $R$ occurs contiguously with S1 (Guthrie, 1935). The exact nature of $R$ may vary (e.g., whether it is represented by pacing or standing still) because this is an example of an instance in which the sensory properties of the "CS" (the context) dominate those of the US to determine the particular form of the CR (see Holland, 1977); such examples are frequent in the conditioning literature (Mackintosh, 1983, pp. 67-76). Given the diverse nature of stimuli collectively referred to as "contextual," we would expect variation in the form of the CR. Thus, the fact that these effective CSs may differ among birds accounts for high between-subject variability, and the contiguity-frequency notion accounts for high withinsubject consistency (stereotypy).

The observed behaviors were highly stereotypic and reminiscent of "habits" described in general by learning theorists with regard to behaviors occurring after extensive amounts of unvaried training (Adams, 1982; James, 1890; Kimble \& Perlmutter, 1970; Morgan, 1894). The performance observed in random training and the subsequent suppression in autoshaping appear characteristic of
S-R rather than of S-S or R-S processes. For example, since removing the reinforcer was not an effective manipulation (Experiment 1, Phases 2 and 3), apparently the reinforcer plays little role in the maintenance of these associations. Similarly, S-S or R-S processes are presumed to be more sensitive to change in the frequency of reinforcement; again, this manipulation had no effect on the behaviors observed here (Experiment 3).

An account of learning in random training in terms of S-R processes allows for concurrent processing of these S-R associations with the S-S associations presumed to underlie keypecking in autoshaping, the latter assumption resting largely on the persistence of keypecking in omission schedules (Williams \& Williams, 1969). Thus, we can suppose that when the autoshaping contingency is introduced, the pairing of keylight (S2) with food (S3) results in keypecking, due to $\mathbf{S 2 - S 3}$ associations, which neither compete with nor replace the S1-R associations. The effectiveness of the S2-S3 contingency would, of course, depend on the distinctiveness and location of the cues used as "S2" (see Boakes, 1977). There is less variability among subjects here because the nature of S2-the keylight-is determined. Since contextual stimuli are still present in autoshaping, $R$ may continue to occur and the S1-R associations may be preserved, again by the repetition of $R$ in the presence of S1. Retardation of acquisition in autoshaping, then, is dependent upon the extent to which the bird continues to exhibit $R$, which is dependent, in turn, upon its incompatibility with the behaviors engendered by the autoshaping contingency. For example, if the bird is pacing in random training when the autoshaping contingency is introduced, this pacing may continue because supporting contextual stimuli (S1) are still present and the pacing may reduce the opportunity for the pigeon to be exposed to the key-food (S2-S3) pairings that result in keypecking; thus, acquisition is retarded. This relationship was observed in Experiment 3 here, as well as in the restraint experiment reported by Locurto et al. (1980). Obviously, a change in context should make $R$ less likely to occur and should reduce potential retardation, as Tomie (1976a, 1976b, 1981) found. The subsequent suppression of the asymptotic response rate may then be due to the compatibility of the behaviors representative of the S1-R associations with those produced by the autoshaping contingency. For example, autoshaping itself generates pacing, which may combine with the tendency of S1 to promote pacing, and thus suppress keypecking. We have some support for this notion in Experiment 2 (Part 2, but not in Part 1), in which suppression of keypecking in autoshaping was related to pacing in random training. The "serial" characteristic of the asymptotic suppression - that it is observed only if initial, and not later, training is random-is understandable if the S1-R sequence is representative of a behavioral sequence, as was consistently observed here. Once established, such sequences are difficult to modify (see Schwartz, 1980).

This theorizing appears to be useful in addressing several issues that have been problematic in the random CS/US literature. For example, according to this notion, retarded 
acquisition and asymptotic suppression are determined not by associative competition or limitation but by the compatibility of behaviors generated by the S2-S3 and the S1-R contingencies. In other species and other preparations besides those of pigeons and appetitive autoshaping, these behaviors may be more or less dissimilar (see Boakes, 1977; Farwell \& Ayres, 1979), and thus we might observe retarded acquisition but not asymptotic suppression (Brandon et al., 1982). An S-R analysis is not necessary to deal with the observation that random training after autoshaping (the latter of which ensures the formation of S2-S3 associations) results in the cessation of keypecking to $S 2$. This may be explained by the fact that $\mathrm{S} 2$ and $\mathrm{S} 3$ are no longer paired (e.g., Gamzu \& Williams, 1971, 1973) or because the change in contingency is confounded with an increased density of reinforcement, which also may suppress responding (Gibbon, Locurto, \& Terrace, 1975; Jenkins, Barnes, \& Barrera, 1981). However, the S-R analysis is useful in accounting for the observation that reacquisition is faster when pigeons are reexposed to autoshaping following CSalone extinction rather than after random training (Tomie, Hayden, et al., 1980, 1981). Specifically, we observed that CS-alone training uniquely attenuated the retardation of acquisition, but had no effect on the asymptotic suppression (Experiment 1). In terms of our hypothesis, these data imply that CS-alone treatment extinguishes behaviors that are incompatible with keypecking but not those that are compatible with keypecking. It follows, then, that reacquisition of keypecking should be faster after CS-alone extinction than after random training. Finally, the observation that the omission of food after extensive random training of birds with a history of initial autoshaping results in the reemergence of keylight-specific keypecking (Brandon, 1981; Durlach, 1986; Lindblom \& Jenkins, 1981) can be dealt with in terms of the integrity of the S2-S3 association (since S1-R is not competitive with that association) and to a substantial change in stimulus conditions that is incurred by the omission of an event as potent as the presentation of food. Transitory display of keypecking may be similar to what Pavlov called "disinhibition," where a change in stimulus conditions during extinction treatment resulted in the temporary reemergence of the previously acquired CR (Pavlov, 1927).

Greater parsimony is achieved with a single-process account. One might consider that both the activity $\mathrm{CR}$ and the keylight CR represent associations with the memory of food. An account of such processes has been offered by Konorski (1967), who suggested that contextual cues should sustain CRs that reflect preparation for the US, whereas more discrete, short cues-such as keylightsshould sustain CRs that reflect consumption of the US. These CRs may or may not interfere with each other. Although this approach suggests that postacquisition treatment of context (such as extinction) should affect the CR, which we did not find here in Experiment 1, this notion does leave us with the novel expectation that random CS/US training might facilitate performance in autoshaping under some circumstances. This was, in fact, demon- strated recently by Tomie (1985), who showed faster acquisition in autoshaping after random training when the CS was a previously static, "contextual" keylight than when it was a novel keylight.

We might also consider an idea that makes no assumptions about the nature of the CR or about the compatibility of various CRs. Rather, we might consider that the difficulty in predicting the behavior that occurs both within and after the random CS/US treatment arises because the experimenter has lost information about the events as they occur in the experiment. (This may follow from the fact that a frequent technique in random CS/US conditioning is to let a random probability generator determine the order and occurrence of the CSs and the USs. Thus, each session differs for each subject, and there is no way of knowing the exact characteristics of the treatment.) If the various CS-to-US and US-to-CS intervals were described and/or controlled, it might be apparent that whether a CS is made excitatory or inhibitory as a result of USs programmed in the absence of the CS depends at least in part on the USs that occur in the period prior to the CS so as to produce inhibitory conditioning, which may or may not be offset by excitatory conditioning produced by other USs that occur in the period following the CS. It is possible, thus, that a random CS/US program produces not only conditioning to contextual cues, but also various excitatory or inhibitory keylight-food associations depending upon the occasions for backward, simultaneous, and forward pairings which the experimenter provides but of which no account commonly is made. In an application of a real-time model of classical conditioning (Wagner, 1981), which describes intratrial events that are of special import to a "random" CS/US schedule, Wagner and Larew (1985) showed that CER conditioned responding was less than what would be expected on the basis of the occasional "forward" CS-US pairings that were given and that "unpaired" US presentations depressed net excitatory learning, at least in part, via the conditioning of contextual cues and, in part, via inhibitory conditioning. This kind of approach is supported by the observations reported by Benedict and Ayres (1972) that what is crucial to the "truly random effect" in rats is the exact nature of the random schedule employed.

\section{REFERENCES}

ADAMS, C. D. (1982). Variations in the sensitivity of instrumental responding to reinforcer devaluation. Quarterly Joumal of Experimental Psychology, 348, 77-98.

ANGER, D., \& ANGER, K. (1976). Behavior changes during repeated eight-day extinctions. Journal of the Experimental Analysis of Behavior, 26, 181-190.

ANronitis, J. J. (1951). Response variability in the white rat during conditioning, extinction, and reconditioning. Journal of Experimental Psychology, 42, 273-281.

BALSAM, P. D. (1984). Bringing the background to the foreground: The role of contextual cues in autoshaping. In M. Commons, R. Herrnstein, \& A. R. Wagner (Eds.), Quantitative analyses of behavior: Vol. 3. Acquisition. Cambridge, MA: Ballinger.

BAlsam, P. D. (1985). The functions of context in learning and per- 
formance. In P. D. Balsam \& A. Tomie (Eds.), Context and learning (pp. 1-21). Hillsdale, NJ: Erlbaum.

Balsam, P. D., \& SCHWARTZ, A. (1981). Rapid contextual conditioning in autoshaping. Journal of Experimental Psychology: Animal Behavior Processes, 1, 382-393.

Benedict, J. O., \& AYres, J. J. B. (1972). Factors affecting conditioning in the truly random control procedure in the rat. Journal of Comparative \& Physiological Psychology, 78, 323-330.

BoAkes, R. A.(1977). Performance on learning to associate a stimulus with positive reinforcement. In H. Davis \& M. B. Hurwitz (Eds.), Operant-Pavlovian interactions. Hillsdale, NJ: Erlbaum.

BRANDON, S. E. (1981). Key-light-specific associations and factors determining key pecking in noncontingent schedules. Journal of Experimental Psychology: Animal Behavior Processes, 7, 348-361.

Brandon, S. E., Satake, N., \& Bitterman, M. E. (1982). Performance of goldfish trained on multiple schedules of responseindependent reinforcement. Journal of Comparative \& Physiological Psychology, 96, 467-475.

Brogden, W. J., Lipman, E. A., \& Culler, E. (1938). The role of incentive in conditioning and extinction. American Journal of Psychology, 51, 109-117.

Bullock, D. H., \& SiTh, W. C. (1953). An effect of repeated conditioning-extinction sessions upon operant strength. Joumal of Experimental Psychology, 46, 349-352.

BuzzARD, J. H., \& HAKE, D. F. (1984). Stimulus control of scheduleinduced activity in pigeons during multiple schedules. Journal of the Experimental Analysis of Behavior, 42, 191-209.

Catania, A. C., \& Keller, K. J. (1981). Contingency, contiguity, correlation, and the concept of causation. In P. Harzem \& M. D. Zeiler (Eds.), Predictability, correlation, and contiguity (pp. 125-167). New York: Wiley.

ClARK, F. C. (1964). Effects of repeated VI reinforcement and extinction upon operant behavior. Psychological Reports, 15, 943-955.

Couvillon, P., Brandon, S. E., Woodard, W. T., \& Bitterman, M. E. (1980). Performance of pigeons in patterned sequences of rewarded and nonrewarded trials. Journal of Experimental Psychology: Animal Behavior Processes, 6, 137-154.

Davis, H., Hubbard, J., Reberg, D. (1973). A methodological critique of research on "superstitious" behavior. Bulletin of the Psychonomic Society, 1, 447-449.

DURLACH, P. J. (1982). Direct measurement of context conditioning in the pigeon. Proceedings of the 53rd Annual Meeting of the Eastern Psychological Association. Baltimore, MD: Eastern Psychological Association.

Durlach, P. (1984). Pavlovian learning and performance when CS and US are uncorrelated. In M. Commons, R. Herrnstein, \& A. R. Wagner (Eds.), Quantitative analysis of behavior: Vol. 3. Acquisition. Cambridge, MA: Ballinger.

DuRLACH, P. (1986). Explicitly unpaired procedure as a response elimination technique in autoshaping. Journal of Experimental Psychology: Animal Behavior Processes, 12, 172-185.

Engberg, L. A., Hansen, G., Welker, R. L., \& Thomas, D. R. (1972). Acquisition of key-pecking via autoshaping as a function of prior experience: “Learned laziness?"' Science, 178, 923-925.

FARLEY, J. (1980). Automaintenance, contrast, and contingencies: Effects of local versus overall and prior versus impending reinforcement context. Learning \& Motivation, 11, 19-48.

FARWELL, B. J., \& AYRES, J. J. B. (1979). Stimulus-reinforcer and response-reinforcer relations in the control of conditioned appetitive headpoking ("goal-tracking") in rats. Learning \& Motivation, 10, 295-312.

Gamzu, E. R., \& Williams, D. R. (1971). Classical conditioning of a complex skeletal response. Science, 171, 923-925.

Gamzu, E. R., Williams, D. R. (1973). Associative factors underlying the pigeon's key pecking in autoshaping procedures. Journal of the Experimental Analysis of Behavior, 19, 225-232.

Gamzu, E., Williams, D. R., \& Schwartz, B. (1973). Pitfalls of organismic concepts: “Learned laziness?' Science, 181, 367-368.

Gibbon, J., Locurto, C. M., \& TerRace, H. S. (1975). Signal-food contingency and signal frequency in a continuous trials auto-shaping paradigm. Animal Learning \& Behavior, 3, 317-324.

Gibbon, J., Baldock, M., Locurto, C., Gold, L., \& Terrace, H. S. (1977). Trial and intertrial duration in autoshaping. Joumal of Experimental Psychology: Animal Behavior Processes, 3, 264-284.

Gibbon, J., \& Balsam, P. (1981). Spreading association in time. In C. M. Locurto, H. S. Terrace, \& J, Gibbon (Eds.), Autoshaping and conditioning theory (pp. 219-253). New York: Academic Press.

GUTHRIE, E. R. (1935). The psychology of learning. New York: Harper.

HaLl, G., \&onig, W. K. (1974). Stimulus control after extradimensional training in pigeons: A comparison of contingent and noncontingent training procedures. Journal of Comparative \& Physiological Psychology, 87, 945-952.

HerRnstein, R. J. (1966). Superstition: A corollary of the principles of operant conditioning. In W. K. Honig (Ed.), Operant behavior: Areas of research and application (pp. 33-51). New York: AppletonCentury-Crofts.

Holland, P. C. (1977). Conditioned stimulus as a determinant of the form of the Pavlovian conditioned response. Journal of Experimental Psychology: Animal Behavior Processes, 3, 77-104.

InNis, N. K., Simmelhag-Grant, V. L., \& Staddon, J. E. R. (1983). Behavior induced by periodic food delivery: The effects of interfood interval. Journal of the Experimental Analysis of Behavior, 39, 309-322.

JAMES, W. (1890). The principles of psychology. New York: Holt.

Jenkins, H. M., Barnes, R. A., \& BArRera, F. J. (1981). Why autoshaping depends on trial spacing. In C. M. Locurto, H. S. Terrace, \& J. Gibbon (Eds.), Autoshaping and conditioning theory. New York: Academic Press

Jenkins, H. M., \& Lambos, W. A. (1983). Tests of two explanations of response elimination by noncontingent reinforcement. Animal Leaming \& Behavior, 11, 302-308.

Killeen, P. R., Hanson, S. J., \& Osborne, S. R. (1978). Arousal: Its genesis and manifestations as response rate. Psychological Review, $85,571-581$.

Kimble, G. A., \& Perlmutter, L. C. (1970). The problem of volition. Psychological Review, 77, 361-384.

KONORSKI, J. (1967). Integrative activity of the brain. Chicago: University of Chicago Press.

LINDBLOM, L. L., \& JENKINS, H. M. (1981). Responses eliminated by noncontingent or negatively contingent reinforcement recover in extinction. Journal of Experimental Psychology: Animal Behavior Processes, 7, 175-190.

Locurto, C. M., Travers, T., Terrace, H. S., Gibbon, J. (1980). Physical restraint produces rapid acquisition of the pigeon's key peck. Journal of the Experimental Analysis of Behavior, 34, 13-21.

Lolordo, V. M., McMillan, J. C., \& Riley, A. L. (1974). The effects upon food-reinforced pecking and treadle-pressing of auditory and visual signals for response-independent food. Learning \& Motivation, 5, 24-41.

Mackintosh, N. J. (1973). Stimulus selection: Learning to ignore stimuli that predict no change in reinforcement. In R. A. Hinde \& J. Stevenson-Hinde (Eds.), Constraints on learning. New York: Academic Press.

MACKINTOSH, N. J. (1975). A theory of attention: Variations in the associability of stimuli with reinforcement. Psychological Review, 82 , 276-298.

Mackintosh, N. J. (1983). Conditioning and associative learning. New York: Oxford University Press.

MoRgAN, C. L. (1894). An introduction to comparative psychology. London: Walter Scott.

NORTH, A. J., \& MoRTON, M. L. (1962). Successive acquisitions and extinctions of an instrumental response. Journal of Comparative \& Phsyiological Psychology, 55, 974-977.

Patrerson, J., \& OVermier, J. B. (1981). A transfer of control test for contextual associations. Animal Learning \& Behavior, 9, 316-321.

Pavlov, I. (1927). Conditioned reflexes. Oxford: Oxford University Press.

Pear, J. J., \& Eldridge, G. D. (1984). The operant-respondent distinction: Future directions. Journal of the Experimental Analysis of Behavior, 42, 453-467. 
Randich, A., \& Lolordo, V. M. (1979). Associative and nonassociative theories of the UCS preexposure phenomenon: Implications for Pavlovian conditioning. Psychological Bulletin, 86, 523-548.

RashotTe, M. R., GrifFin, R. W., \& Sisk, C. L. (1977). Second-order conditioning of the pigeon's keypeck. Animal Learning \& Behavior, 5, 25-38.

ReberG, D., Innis, N. K., Mann, B., \& Eizenga, C. (1978). “'Superstitious" behaviour resulting from periodic response-independent presentations of food or water. Animal Behaviour, 26, 507-519.

Rescorla, R. A., Durlach, P. J., \& Grau, J. W. (1985). Context learning in Pavlovian conditioning. In P. D. Balsam \& A. Tomie (Eds.), Context and learning (pp. 23-56). Hillsdale, NJ: Erlbaum.

Rescorla, R. A., \& Wagner, A. R. (1972). A theory of Pavlovian conditioning: Variations in the effectiveness of reinforcement and nonreinforcement. In A. H. Black \& W. F. Prokasy (Eds.), Classical conditioning: II. Current theory and research. New York: AppletonCentury-Crofts.

SCHWARTZ, B. (1980). Development of complex, stereotyped behavior in pigeons. Journal of the Experimental Analysis of Behavior, 33, 153-166.

SKINNER, B. F. (1948). "Superstition"' in the pigeon. Journal of Experimental Psychology, 38, 168-172.

Staddon, J. E. R., \& Simmelhag, V. L. (1971). The "superstition" experiment: A reexamination of its implications for the principles of adaptive behavior. Psychological Review, 78, 3-43.

Timberlake, W., \& LuCas, G. A. (1985). The basis of superstitious behavior: Chance contingency, stimulus substitution, or appetitive behavior? Journal of the Experimental Analysis of Behavior, 44, 279-299.

Tomie, A. (1976a). Interference with autoshaping by prior context conditioning. Journal of Experimental Psychology: Animal Behavior Processes, 2, 323-334.

TomiE, A. (1976b). Retardation of autoshaping: Control by contextual stimuli. Science, 192, 1244-1246.

TOMIE, A. (1981). Effect of unpredictable food on the subsequent acquisition of autoshaping: Analysis of the context-blocking hypothesis. In
C. M. Locurto, H. S. Terrace, \& J. Gibbon (Eds.), Autoshaping and conditioning theory (pp. 181-215). New York: Academic Press.

TOMIE, A. (1985). Effects of test context on the acquisition of autoshaping to a formerly random keylight or a formerly contextual keylight. In P. D. Balsam \& A. Tomie (Eds.), Context and learning (pp. 5772). Hillsdale, NJ: Erlbaum.

TOMIE, A., HAyden, M., \& BIEHL, D. (1980). Effects of response elimination procedures upon the subsequent reacquisition of autoshaping. Animal Learning \& Behavior, 8, 237-244.

Tomie, A., MurPHy, A. L., FATH, S., \& JaCkSON, R. L. (1980). Retardation of autoshaping following pretraining with unpredictable food: Effects of changing the context between pretraining and testing. Learning \& Motivation, 11, 117-134.

Tomie, A., RhoR-STAFFord, I., \& Schwam, K. I. (1981). The retarding effect of the TRC response elimination procedure upon the subsequent reacquisition of autoshaping: Comparison of between- and withinsubjects assessment procedures and the evaluation of the role of background contextual stimuli. Animal Learning \& Behavior, 9, 230-238.

WAgner, A. R., LAREW, M. (1985). Opponent processes and Pavlovian inhibition. In R. R. Miller \& N. E. Spear (Eds.), Information processing in animals: Conditioned inhibition (pp. 233-265). Hillsdale, NJ: Erlbaum.

Wagner, A. R., \& LAREw, M. (1985). Opponent processes and Pavlovian inhibition. In R. R. Miller \& N. E. Spear (Eds.), Information processing in animals: Conditioned inhibition (pp. 233-265). Hillsdale: NJ: Erlbaum.

WARDEN, C. J., \& LUBOW, L. (1942). Effect of performance without reward on the retention of the maze habit in the white rat. Journal of Genetic Psychology, 60, 321-328.

Williams, D. R., \& Williams, H. (1969). Auto-maintenance in the pigeon: Sustained pecking despite contingent nonreinforcement. Journal of the Experimental Analysis of Behavior, 12, 511-520.

(Manuscript received October 15, 1986; revision accepted for publication May 1, 1987.) 